\title{
Unimolecular reaction mechanisms: the role of reactive intermediates*
}

\author{
Hans-Friedrich Grützmacher \\ Lehrstuhl I fur Organische Cheme der Fakultat für Chemıe, Universtat Bielefeld, POB 8640, \\ Unversitatssiraße, W-4800 Bielefeld 1 (Germany)
}

(Received 26 August 1991)

\section{ABSTRACT}

\begin{abstract}
Many unimolecular mass spectrometric fragmentations do not occur directly from the ionized but otherwise intact molecules, but involve isomenzation to reactive intermediates as the critical step of the fragmentation mechanısm During the last few years, distonic ions and ion/neutral complexes have been identified as important intermediates of mass spectrometric fragmentations Examples are taken from the recent literature and from our own unpublished results to llluminate the role of these intermediates, in particular for rearrangement reactions by remote group interaction
\end{abstract}

\section{INTRODUCTION}

The mechanisms of unimolecular fragmentation reactions of energetically excited ions still form the basis for the interpretation of mass spectra and their application to structure analysis, in spite of the much advanced techniques of computer-assisted evaluation of mass spectra. In addition, the reactions of isolated ionic species as studied by the broad collection of mass spectrometric methods permit a profound insight into the principles connecting structure and reactivity. Both aspects ensure a continuing interest in the studies of unimolecular reaction mechanisms of gaseous ions. Impressive instrumentation has been developed over the last two decades for these studies, as outlined by Gross in his keynote lecture of this series at the Bordeaux conference [1]. One of the most important "tools of ion chemistry" available in many laboratories is certainly the technique of tandem mass spectrometry [2], and these methods have been used extensively in various modifications also during the last 3 years to investigate the structures and reactivities of gaseous ions. In addition to the results obtained by these advanced experimental methods, much valuable information (and stimulations) about ion structure and ion reactivity has come from the theoretical approach to gas-phase ion chemistry [3]. However,

\footnotetext{
* Paper presented at the 12th International Mass Spectrometry Conference, Amsterdam, The Netherlands, 26-30 August 1991.
} 


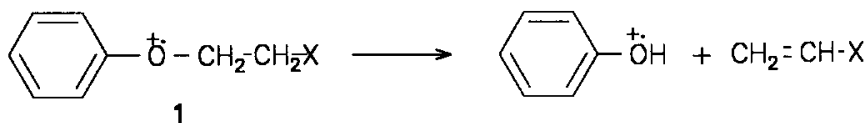

$\mathrm{X}=\mathrm{Cl}, \mathrm{Br}, \mathrm{OCOR}$

$\mathrm{m} / \mathrm{z} 94$

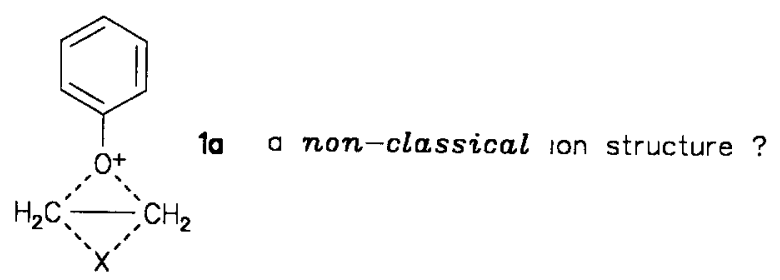

Scheme 1. The "symmetrization" of molecular ions.

from the very first studies of unimolecular reaction mechanisms of organic, metal-organic and element-organic ions in the gas phase it became evident that a careful investigation of ions specifically labelled with stable isotopes is essential to give a correct evaluation of fragmentation mechanisms. Thus, one fascinating aspect of research in the field of unimolecular reaction mechanism is the interdisciplinary character, both with respect to the methods used and with respect to the impact of the results obtained on practical applications and fundamental theories.

The labelling studies of organic ions by mass spectrometry sometimes give rather puzzling results, showing that fragmentations which appear to be "straightforward" processes are in fact the results of rather complicated mechanisms. A typical example is the formation of ions $\mathrm{C}_{6} \mathrm{H}_{6} \mathrm{O}^{++}, m / z 94$, from the molecular ions of 2-phenylethyl halides (1 in Scheme 1), obviously by a 1,2-elimination [4]. However, the electron impact (EI) mass spectra of deuterated derivatives of 1 reveal that both $\mathrm{CH}_{2}$ groups participate in this fragmentation and in fact have become indistinguishable before the reaction. The observation (and the extensive research on non-classical ions at that time) led the authors to suggest the symmetric structure 1a for the molecular ion of 1 [4].

"Symmetrization" [4] of organic molecular ions is often indicated by the results of labelling studies, but is not necessarily due to a symmetric "nonclassical" structure of the ions. This becomes clear from a second example, the fragmentation of the molecular ions of 1,3-di-phenylpropane ( 2 in Scheme 2) by the well-known process [5] of a $\gamma$-hydrogen transfer to the benzene ring and formation of ions $\mathrm{C}_{7} \mathrm{H}_{8}^{+}{ }^{+}[6]$. In this case the labelling experiments showed that the four hydrogen atoms at the four ortho positions of the two benzene rings and the four hydrogen atoms at the two benzylic methylene groups are involved in the process, but not the hydrogen atoms at the meta and para 


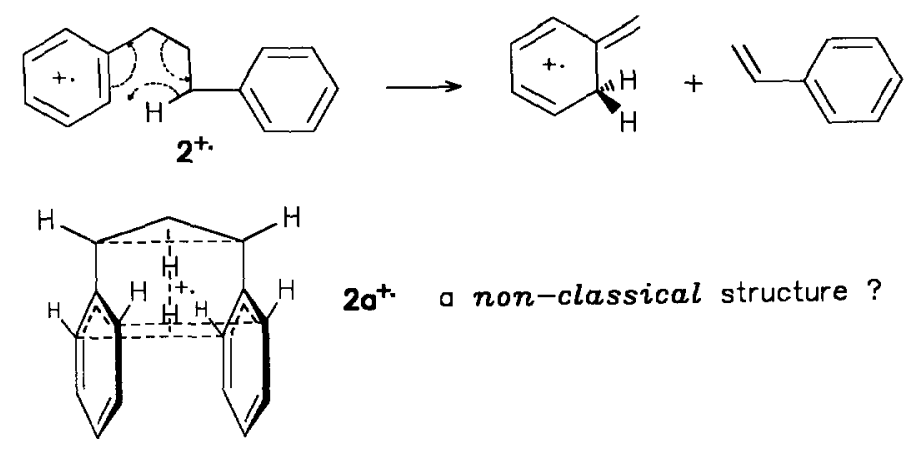

Fast hydrogen exchange by reactive intermediates :
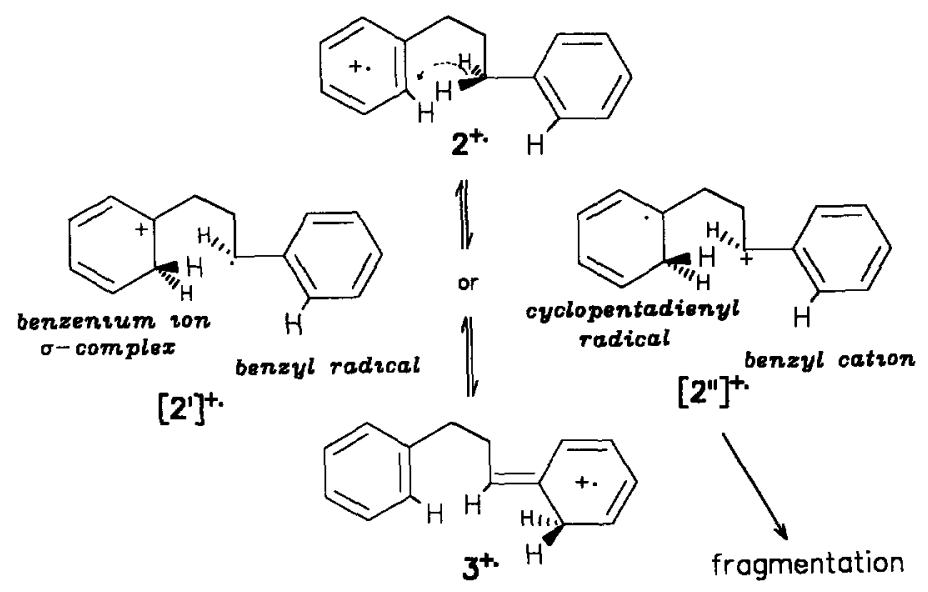

Scheme 2.

positions of the rings. This would correspond to a "symmetrization" of the molecular ion of $\mathbf{2}$ into the rather interesting non-classical structure $\mathbf{2 a}$. However, comparing the label distribution of the fragmentation products as a function of reaction time (ion source and second field-free region (FFR), respectively, of a MAT 311 A mass spectrometer) showed clearly [6b], that the "scrambling" of the eight hydrogen atoms of $2^{++}$is not the result of a static, non-classical ion structure, but is in fact a kinetic phenomenon which is due to fast hydrogen exchanges via the reactive intermediates shown in Scheme 2.

Although mass spectrometry has been (and still is) often used to detect interesting and novel stable structures of ions and neutrals in the gas phase, mass spectrometry is in principle a kinetic technique which mainly reflects the reactive configurations of fragmenting ions. It is now generally recognized that in many cases the outcome of a fragmentation reaction is determined by the reactive intermediates of the process. In the case of $2^{+}$the reactive 


$$
\begin{aligned}
& \mathrm{CH}_{2}-\underline{\mathrm{O}}^{+} \mathrm{H}_{2} \quad \mathrm{CH}_{2} \mathrm{CH}_{2}-\underline{\mathrm{O}}^{+} \mathrm{H}_{2} \quad \mathrm{CH}_{2} \mathrm{CH}_{2} \mathrm{CH}_{2}-\underline{\mathrm{O}}^{+} \mathrm{H}_{2} \\
& \alpha \text {-distonic } \quad \beta \text {-distonic } \quad \gamma \text {-distonzc } \\
& \mathrm{CH}_{2} \mathrm{~F}^{+} \mathrm{H} \quad \mathrm{CH}_{2} \mathrm{Cl}^{+} \mathrm{H} \quad \mathrm{CH}_{2} \mathrm{CH}_{2} \mathrm{~N}^{+} \mathrm{H}_{3} \quad \mathrm{CH}_{3} \mathrm{CH}-\mathrm{S}^{+} \mathrm{H}_{2} \\
& \underset{+\underline{\mathrm{O}} \mathrm{H}}{\mathrm{CH}_{2} \mathrm{CH}_{2} \mathrm{CH}_{2}-\underset{\mathrm{C}}{\mathrm{H}}-\mathrm{R}} \quad \mathrm{CH}_{2}-\underline{\overline{\mathrm{O}}}-\mathrm{C}^{+} \mathrm{H}_{2} \leftrightarrow \mathrm{CH}_{2}-\underline{\mathrm{O}}^{+}=\mathrm{CH}_{2}
\end{aligned}
$$

Scheme 3

intermediate (a distonic ion, see below) arises from the migration of a hydrogen atom from a benzylic position to the ortho position of the remote phenyl group (Scheme 2). Interestingly, two different intermediates ("electromers" [6]) $\mathbf{2}^{\prime}$ and $\mathbf{2}^{\prime \prime}$, respectively, may be formed during the isomerization of $2^{+}$into $3^{-+}$. Intermediate $2^{\prime}$ results from a hydrogen atom transfer and is composed of a benzenium ion (a protonated benzene) and a benzyl radical, while intermediate $\mathbf{2}^{\prime \prime}$ is formed by a hydride transfer and corresponds to a cyclohexadienyl radical and a benzyl cation. Different reactivities are expected for these two intermediates: in the benzenium structure of $\mathbf{2}^{\prime}$ the extra proton should exchange quickly with all other $\mathbf{H}$ atoms at the aromatic rings [7], while no additional $\mathrm{H}$ shifts are expected within the cyclohexadienyl radical structure of 2" (for a review of the properties of aromatic radicals and arenium ions, see ref. 7). Thus only intermediate 2 " agrees with the experimental results, showing how important a careful study and consideration of reactive intermediates is for a profound understanding of mass spectrometric fragmentation reactions. It is the aim of this account to present and discuss some examples of unimolecular reaction mechanisms illustrating this point. Two types of reactive intermediate will be discussed: distonic ions and ion/neutral complexes. Both intermediates have raised considerable and increasing interest during the last 5 years for the discussion of unimolecular reactions of gaseous ions and have been recently reviewed $[8,9]$.

\section{INTERMEDIATE DISTONIC IONS}

Distonic ions constitute a special class of radical ions, in which the (positive or negative) charge and the radical electron are localized at separate atoms or reside in separate local molecular orbitals. Some examples are shown in Scheme 3.

Although distonic ions have been postulated for some time as intermediates of mass spectrometric fragmentations (see for example Scheme 2) [6], it is only recently that their special role in gas-phase ion chemistry has been confirmed by theoretical methods [10]. In particular, the observation that many distonic ions are more stable than the isomeric conventional molecular ions has stimulated a search for these unconventional ion structures and a study of their reactivity. Small distonic ions, i.e. ylid ions or $\alpha$-distonic ions [8], are 


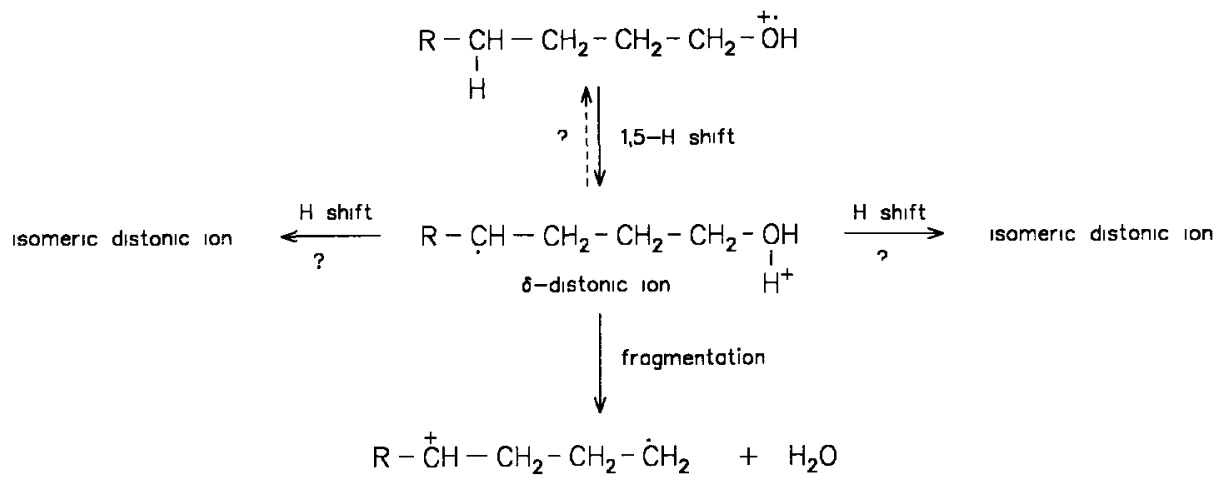

Scheme 4 Two-step elımınations with hydrogen transfer.

especially stable and, moreover, are separated from their conventional isomers by quite large energy barriers. Thus a mutual interconversion between these distonic ions and the isomeric molecular ions is slow or does not occur at all. Since the neutral counterpart of an $\alpha$-distonic ion is either missing or difficult to handle by the usual inlet system of a mass spectrometer, these thermodynamically and kinetically stable distonic ions are prepared from larger molecular ions by elimination processes; a typical example is the formation of ${ }^{\cdot} \mathrm{CH}_{2} \mathrm{ClH}^{+}$from the molecular ion of chloroacetic acid by elimination of $\mathrm{CO}_{2}$ :

$\left[\mathrm{Cl}-\mathrm{CH}_{2}-\mathrm{CO}-\mathrm{O}-\mathrm{H}\right]^{++} \rightarrow \mathrm{H}^{+} \mathrm{Cl}-\mathrm{CH}_{2}+\mathrm{CO}_{2}$

However, with respect to their role as reactive intermediates of mass spectrometric fragmentation reactions those distonic ions are of more interest which arise from the conventional molecular ions by isomerization. Typically, the isomerization occurs by bond cleavage of a cyclic molecular ion or by an internal hydrogen abstraction. Thus the distonic ion ${ }^{\circ} \mathrm{CH}_{2}-\mathrm{O}-\mathrm{CH}_{2}^{+}$may be formed by cleavage of the $\mathrm{C}-\mathrm{C}$ bond in oxirane radical cations [11], and an intermolecular hydrogen abstraction is usually the initial step for the loss of $\mathrm{H}_{2} \mathrm{O}$ and related elimination processes (see Schemes 2 and 4).

Clearly the mechanism of the elimination depends critically on the properties of the initially formed distonic ion as a reactive intermediate. In the case of the water elimination from the molecular ions of long-chain primary alcohols shown in Scheme 4, the $\delta$-distonic ion generated by the initial $1,5-\mathrm{H}$ shift is kinetically unstable with respect to the elimination of $\mathrm{H}_{2} \mathrm{O}$. As a consequence the hydrogen migration is nearly unidirectional, and little hydrogen exchange accompanies the loss of $\mathrm{H}_{2} \mathrm{O}$. A contrasting example is the elimination of styrene from the molecular ions of 1,3-diphenylpropane 2 (Scheme 2) already discussed. Here the stability of the intermediate distonic ion results in extensive hydrogen scrambling during the elimination process. Besides hydrogen scrambling, hydrogen migrations in the initially formed 
distonic ion may alter dramatically the fragmentation route. These effects are observed particularly for metastable ions. Therefore their influence on the fragmentation mechanism is important in an analytical application of tandem mass spectrometry because they may mimic an isomeric structure for the analyte. A recent example has been discussed by Longevialle and co-workers [12] for the electron impact induced fragmentations of large-ring primary, secondary and tertiary cycloalkylamines. High energy molecular ions decomposing in the ion source follow the reaction pathways known from small-ring cycloalkylamines, i.e. $\alpha$-cleavage in the extra-annular $\mathrm{N}$-alkyl chain and intraannular $\alpha$-cleavage yielding a distonic ion, which rearranges to an enamine radical cation and eventually fragments to $\mathrm{R}_{2} \mathrm{~N}^{+}=\mathrm{CH}-\mathrm{CH}=\mathrm{CH}_{2}, \mathrm{~m} / z$ $(54+2 \mathrm{R})$ [13]. However, this latter process is only a minor one for metastable ions which fragment instead by losses of a series of alkyl radicals which originate also from the carbocyclic ring. An example and the explanation for these observations by a series of internal hydrogen abstractions is given in Scheme 5 .

The key step is the formation of the distonic immonium ion $\mathbf{d}$ by the intra-annular $\alpha$-cleavage as usual. However, $\mathbf{d}$ rearranges not only by intramolecular hydrogen abstractions to the enamine radical cation e but also to another distonic ion $\mathbf{d}^{\prime}$ by hydrogen abstraction from the $\mathrm{N}$-alkyl group. Ring closure of $\mathbf{d}^{\prime}$ to a cyclic amine molecular ion exposes the original ring as a side-chain, which is eventually lost as an alkyl radical. This ring closure is a process discovered some years ago by Richter et al. [14] in the case of intermediate distonic ions formed from small-ring cycloamines.

The latter reaction mechanism suggests an intermediate distonic ion as the origin of a skeletal rearrangement of the molecular ion. Three other examples of this important role of intermediate distonic ions follow. It is well known [13] that the EI mass spectra of primary $n$-alkyl amines exhibit a small peak at $m / z 44$ besides the base peak at $m / z 30$ of the immonium ion $\mathrm{CH}_{2}=\mathrm{NH}_{2}^{+}$, which is the expected $\alpha$-cleavage product. The intensity of the ions $m / z 44$ increases very much in the mass-analysed kinetic energy (MIKE) spectra of the molecular ions of primary amines, however, and it has been shown [15] that this is due to an isomerization of an intermediate distonic ion $\mathbf{p}$ with the 1 -aminoalkane structure into another distonic ion $\mathbf{s}$ with a 2-aminoalkane structure by a $1,2-\mathrm{NH}_{3}$ shift (Scheme 6).

The formation and interconversion of $\mathbf{p}$ and $\mathbf{s}$ is accompanied by additional hydrogen shifts, but the $1,2-\mathrm{NH}_{3}$ shift is particularly important and makes the traditional explanation of the formation of ions $m / z 44$ in the EI mass spectra by an $\mathrm{SN}_{1}$ process obsolete.

Especially intriguing are skeletal isomerizations in intermediate distonic ions by 1,2-shifts of hydroxycarbenes. A famous example is the rearrangement 

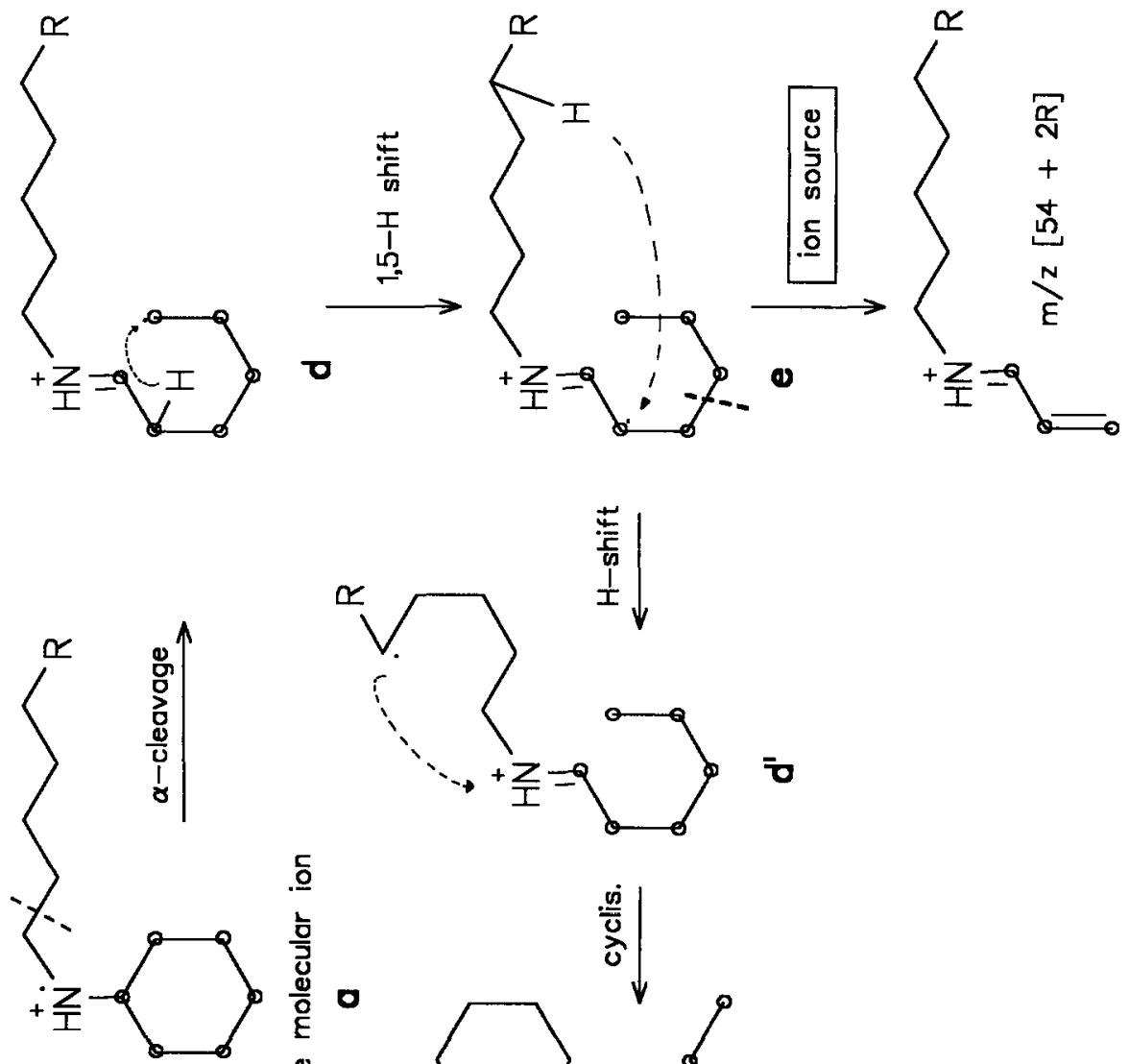

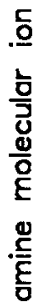
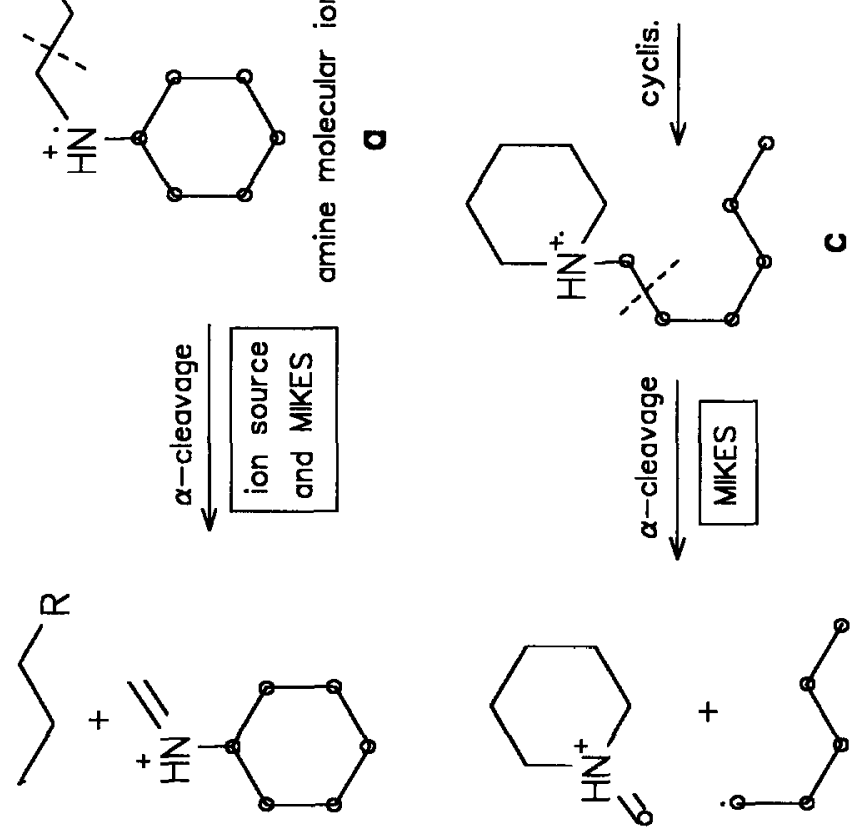

品 

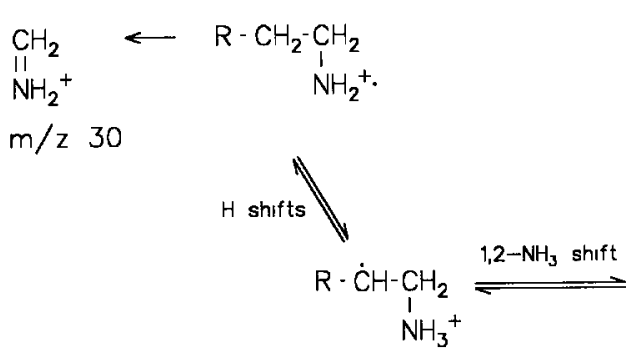

$p$

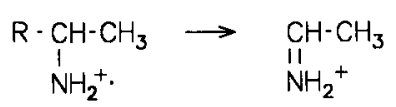

$\mathrm{m} / \mathrm{z} 44$

Scheme 6. 1,2- $\mathrm{NH}_{3}$ shift in amıne ions

of methyl isobutyrate molecular ions prior to the loss of methyl, as shown in Scheme $7\left(\mathrm{R}=\mathrm{CH}_{3}\right)$.

The direct loss of $R^{\prime}$ from the molecular ion would give rise to an energetically unfavourable fragment ion. Hence the molecular ion takes a detour by an initial 1,4-H shift yielding the distonic ion a, followed by a 1,2 shift of a hydroxy methoxycarbene unit (1on b) and another 1,2- $\mathrm{H}$ shift (ion c) before $\mathrm{R}^{\cdot}\left(=\mathrm{CH}_{3}\right)$ is eventually lost and stable protonated methyl acrylate is formed. Originally it was proposed that this is the only route for the formation of $[\mathrm{M}-\mathrm{R}]^{+}$ions $\left(\mathrm{R}=\mathrm{CH}_{3}\right)$ [16]. Subsequently it has been demonstrated that the mechanism for the loss of methyl from methyl isobutyrate molecular ions depends critically on the internal energy of the ions and the reaction time [17], and that methyl loss from the intermediate distonic ion $\mathbf{b}$ is also important. In fact, if R corresponds to a good "leaving group", i.e. Br or I, the direct loss of $\mathrm{R}^{\prime}$ ' is observed, yielding the destabilized $\alpha$-carbomethoxy carbenium ions $[18,19]$. These ions are easily distinguished from the isomeric protonated acrylates, their MIKE spectra exhibiting an exceptional broad peak for the loss of CO [18]. Anyhow, the rearrangement by a 1,2-shift of hydroxycarbene and its derivatives in intermediate distonic ions is firmly established by experimental and theoretical studies, and is frequently observed during the decomposition of aliphatic carbonyl compounds.

Of course, the characteristic fragmentation of ionized aliphatic carbonyl compounds is the McLafferty rearrangement (see for example, ref. 13), starting with a 1,5-H shift to generate an intermediate distonic ion (Scheme 8) [20]. However, besides bond cleavage to yield the products of the McLafferty rearrangement, this distonic ion must be also the source of further skeletal rearrangements of the carbonyl molecular ion. This follows from labelling studies $[21,22]$ as well as from the observation that pairs of certain isomeric heptanone molecular ions give very similar collisional activation (CA) spectra [23]. A typical duo of such isomeric heptanones is shown in Scheme 8, and the isomeric distonic ions, intermediates of the McLafferty rearrangement, can probably interconvert by a dissociation/re-addition mechanism of the alkene 


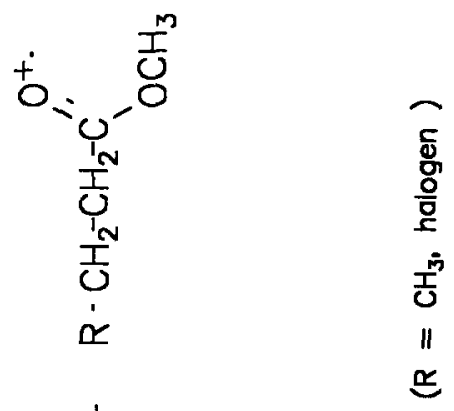

王」蒙

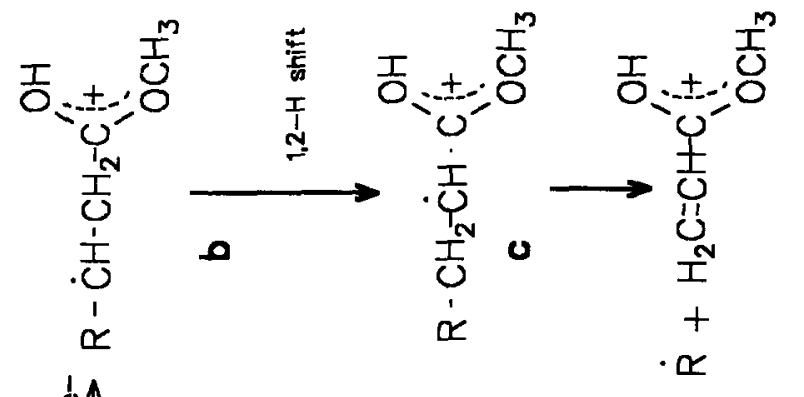

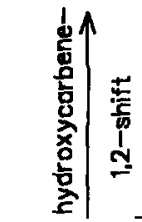
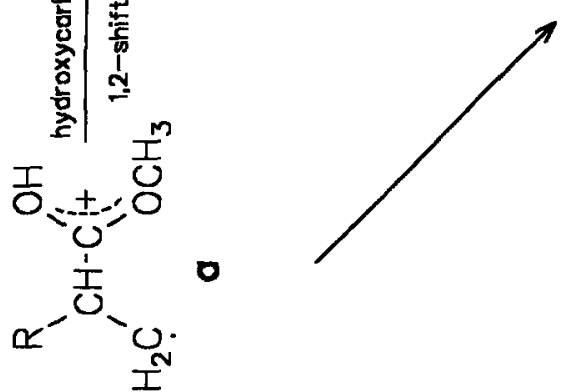

$\underset{⿱ 亠 乂}{ \pm} \uparrow$

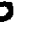

음

寝

$\llbracket$

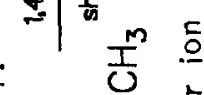

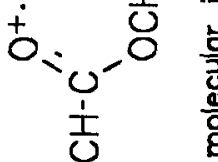

点 䓵

$\alpha \cdot \underbrace{}_{M} \frac{d}{g}$

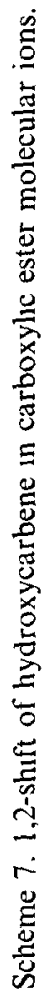




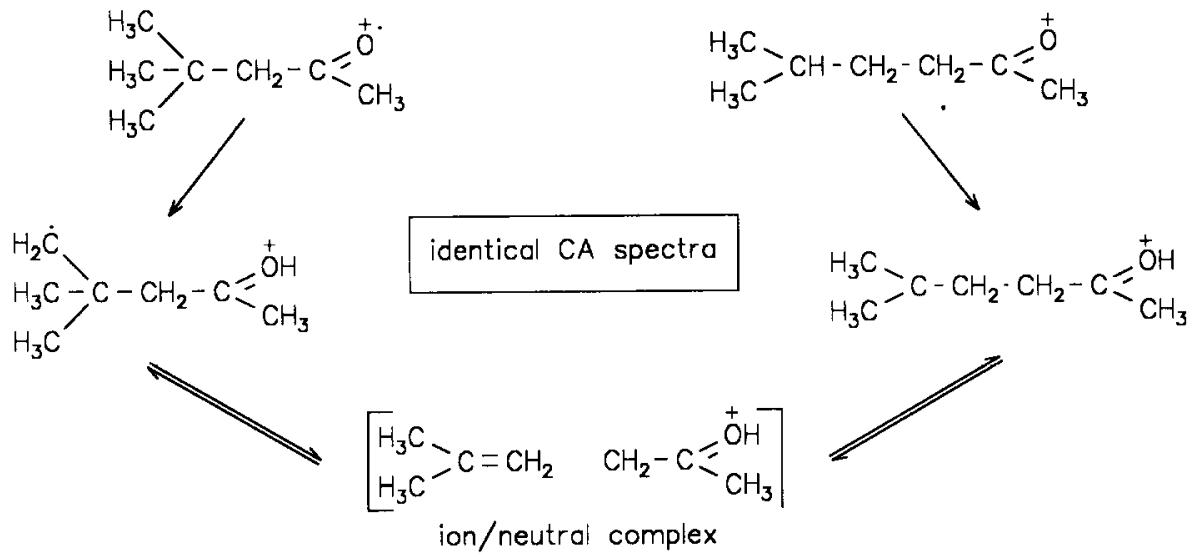

Scheme 8

and enol radical ion. This would imply that not only distonic ions but also ion/neutral complexes are reactive intermediates of the McLafferty rearrangement. It should be noted, however, that the main process observed in the CA and MIKE spectra of the heptanone radical ions shown in Scheme 8 is not the dissociation of the ion/neutral complex, as expected for an intermediate complex. Instead, the loss of an ethyl radical dominates the MIKE and CA spectra. This indicates a further and more complex rearrangement, and more experimental data are necessary to establish firmly the mechanism of these rearrangements.

\section{INTERMEDIATE ION/NEUTRAL COMPLEXES}

The importance of intermediate ion/neutral complexes in certain mass spectrometric fragmentations is now generally accepted [9]. This account will not enter the controversy about the correct definition of these complexes but follow the arguments of Morton and co-workers [24]. Intramolecular processes in long-lived ion/neutral complexes are well established for bimolecular ion/ molecule reactions, and the properties of intermediate ion/neutral complexes during unimolecular dissociations can be understood by viewing a mass spectrometric dissociation as a "reversed reactive half-collision". According to this model [24] the dissociation of an ion $\mathrm{R}-\mathrm{Y}^{+}$by bond cleavage (heterolytic in even-electron systems, homolytic in odd-electron systems) will pass a "locked rotor" critical configuration [24cd] before the dissociation products will lose contact at infinite separation (Scheme 9). With respect to the association reaction this locked rotor critical configuration corresponds to that position on the reaction coordinate where the components of the encounter complex have to align the orbitals at the reaction centres to form the covalent bond. Once the system has passed this critical configuration on the dissociation 


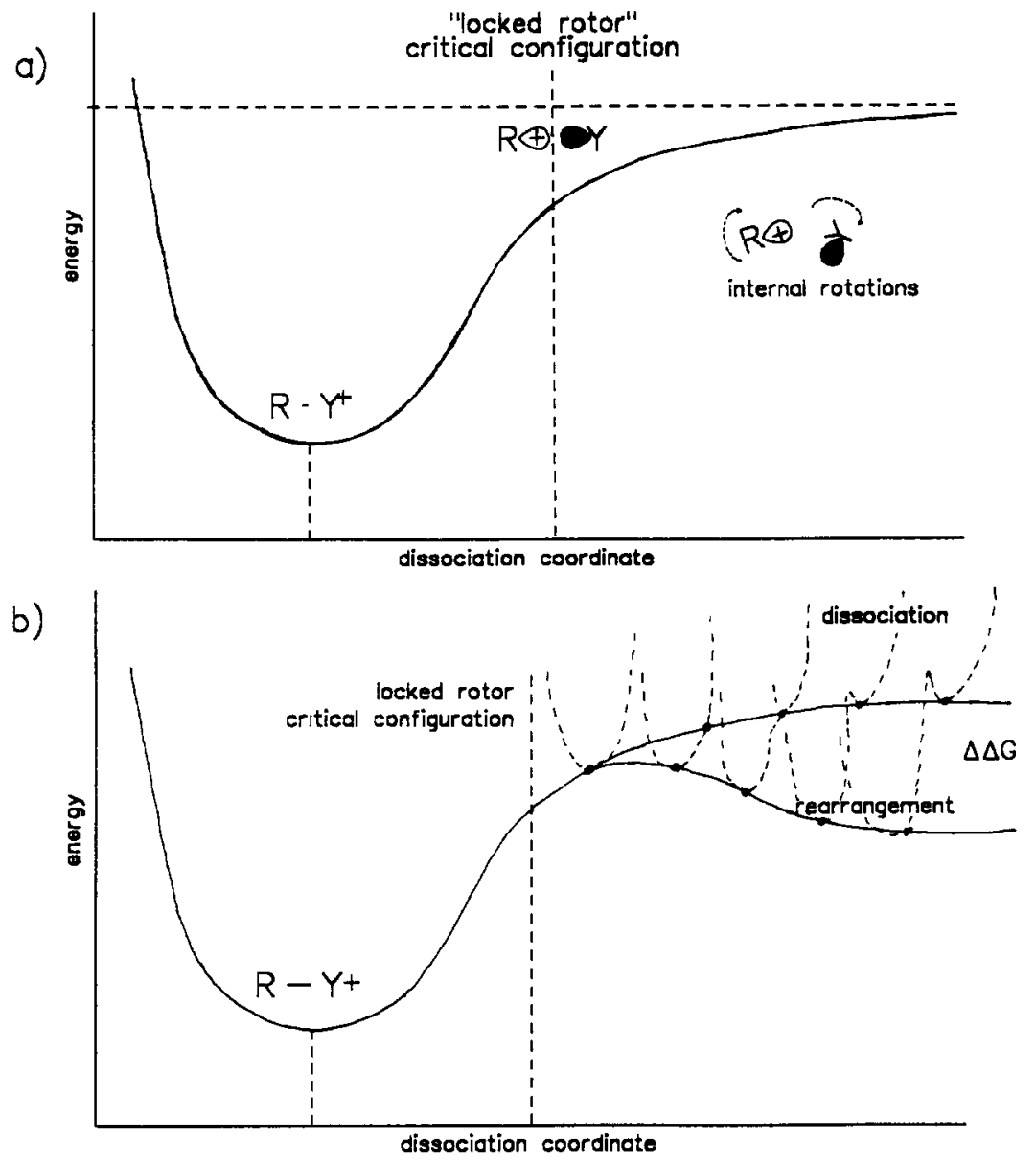

Scheme 9. Definition of intermediate ion/neutral complexes.

route, the ionic and neutral components are held in association by ion-dipole and ion-induced dipole forces, but the components may alter their relative orientations or rotate against each other (Scheme 9(a)). In the discussion of mechanistic aspects of mass spectrometric fragmentation, any dissociating system between the locked rotor configuration and infinite separation is considered as an intermediate ion/neutral complex. By this definition an ion/neutral complex always has to be an intermediate state of a dissociating ion, similar to an intimate or contact ion pair for $\mathrm{SN}_{1}$-reactions in solution [25], and the only question is what are the consequences for the mechanism of the mass spectrometric fragmentation.

In principle there are four possibilities for the further fate of an intermediate ion/neutral complex: (i) internal return to the starting ion, (ii) dissociation into the components, (iii) rearrangement of the components 
(primarily of the ionic component), and (iv) fragmentation by an intermolecular ion/molecule reaction. Since the components $R^{+}$and $Y$ possess the potential energy for dissociation, a recombination of $\mathrm{R}^{+}$and $\mathrm{Y}$ (process (i)) would correspond to radiative association which has not been studied under these circumstances. Dissociation into the components (process (ii)) is the normal reaction of the complex and will occur if sufficient energy from the internal degrees of freedom of the components is directed into relative motion of $\mathrm{R}^{+}$and $\mathrm{Y}$ (the dissociation coordinate). Both processes (i) and (ii) do not alter the products of the mass spectrometric fragmentation as expected from "conventional" mechanisms but do affect the dynamics and the rate of the dissociation [26]. However, since ions of low internal energy may spend quite a time in the state of an intermediate ion/neutral complex some internal ion/molecule reactions may have occurred before dissociation. These are often hydrogen exchanges between the components which are detected from the decompositions of deuterated parent ions [9,24]. This is in analogy with the $\mathrm{H} / \mathrm{D}$ exchanges already observed years ago in otherwise unreactive ion/neutral complexes formed by collisions of $\mathrm{OD}^{-}$with certain hydrocarbons [27].

In contrast to processes (i) and (ii) the products of the processes (iii) and (iv) are structurally different from those of the direct dissociation of the intermediate complex. These processes become possible if a new and energetically less expensive reaction channel branches from the dissociation pathway after the locked rotor critical configuration, as pictured in Scheme 9(b). However, since there is another tight transition state present in the new reaction channel owing to the chemical reaction, the branching ratio between this new reaction and the dissociation of the complex should depend very much on the difference $\Delta \Delta G$ of the heats of reaction for both reaction pathways and on the internal energy of the system. For small and even moderate $\Delta \Delta G$ the dissociation pathway is very much favoured for ions of high internal energy by entropic effects. Thus a situation as shown in Scheme 9(b) will lead to very different fragmentation behaviour of high energy and low energy parent ions reacting in the ion source and in an FFR, respectively, of a mass spectrometer. This may be a nuisance for the analyst working with one of the modern devices operating with a variable time delay between ion formation and ion detection because the peak pattern of the mass spectra changes very much with the adjustment of the apparatus. This time and energy dependence of unimolecular fragmentations is a very fascinating phenomenon for fundamental research on the dynamics of chemical reactions, however. The ion/neutral complexes intermediate to unimolecular fragmentations have just enough energy to dissociate by new and energetically favourable reactions, and these low energy complexes are difficult to prepare otherwise. The intramolecular reaction of low energy ion/neutral complexes allow the study of proximity effects and effects of orientation of two reactants in close 


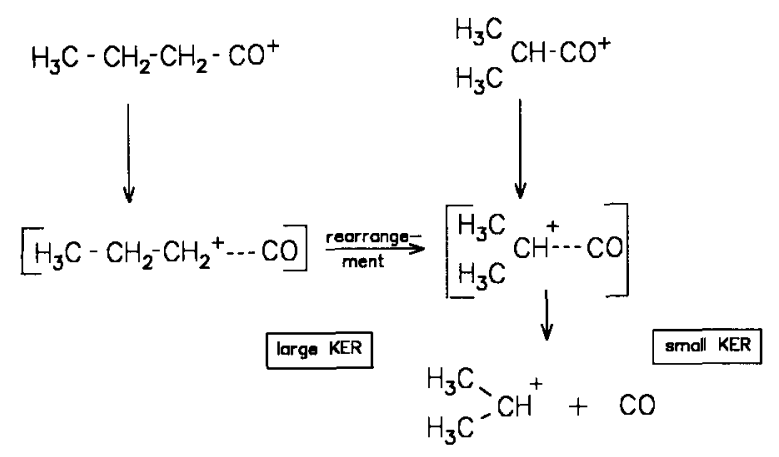

Scheme 10. Rearrangement of the "incipient carbenium ion".

contact with each other. These effects are, for example, essential for an understanding of the mechanisms of stereoselective synthesis. Another recent technique for preparing ion/neutral complexes of low internal energy is the multiphotoionization of van der Waals complexes [28]. However, this very sophisticated technique is at the moment difficult to perform with molecules large enough to bridge the gap between physical experiment and chemical synthesis.

A situation corresponding to the energy profile in Scheme 9(b) is most likely to be observed for an exothermic rearrangement of one of the components of the intermediate ion/neutral complex, because this rearrangement becomes possible at the moment when the orbital constraint at the reaction centres of the parent ion is released at the locked rotor critical configuration. Exothermic rearrangements of carbenium ions by 1,2-hydrogen and 1,2-alkyl shifts exhibit quite small activation barrier [25(a)]. Thus the observation of a rearrangement of "incipient carbenium ions" (Scheme 10) during mass spectrometric fragmentations by Bowen and Williams [29] was one of the early manifestations of intermediate ion/neutral complexes. The exothermic rearrangement of the carbenium ion releases "non-fixed" energy to the complex, which dissociates and shows its excess energy by a large kinetic energy release [30]. Subsequent to this observation, numerous other examples of rearrangements of carbenium ions in intermediate ion/neutral complexes have been observed, and in view of the exorbitant tendency of carbenium ions to undergo rearrangements, process (iii) may in fact describe the "normal" mechanism for the generation of carbenium ions by mass spectrometric fragmentations.

A fragmentation mechanism according to process (iv) may be anticipated if the intramolecular ion/neutral reaction yields stable products and if the steric requirements of its critical configuration (entropy effects!) are not very restrained. This is very likely the case in the elimination of alkanes in competition with the loss of an alkyl radical by an $\alpha$-cleavage. This and similar fragmentations of aliphatic alcohols, ketones and ethers have been studied in 

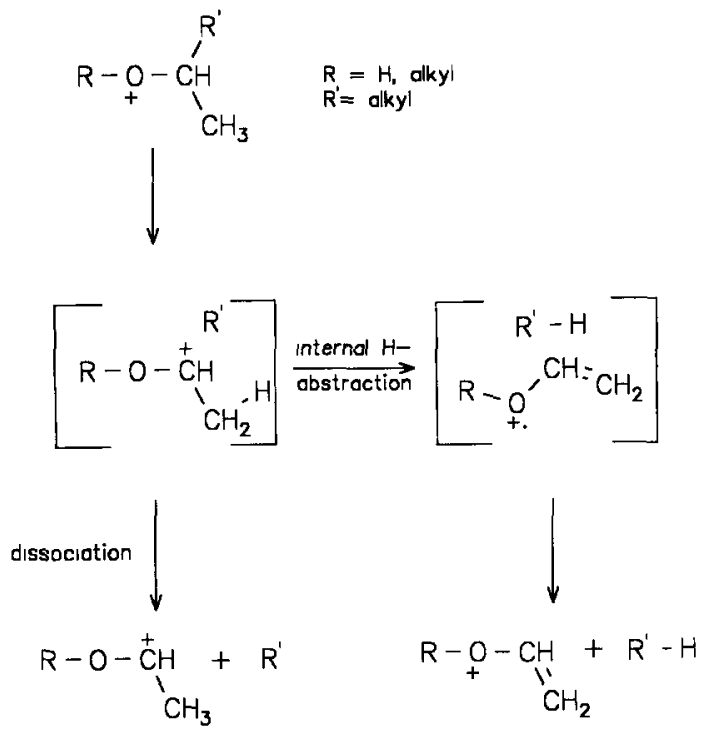

Scheme 11. Alkane vs. alkyl loss.

detail by several groups (for a review see ref. 9, and refs. 31-33). The fragmentation of ionized secondary ethers is presented as an example in Scheme 11. A study of the energy dependence of the alkane elimination [32b] from aliphatic ethers shows that this process is competitive only in a narrow sector of internal energy, and that the relative rates for the loss of an alkyl radical and the corresponding alkane change very rapidly in favour of alkyl loss with increasing internal energy. A priori, this behaviour could also be explained by a conventional mechanism for the alkane loss with a rather asymmetric transition state in competition with alkyl radical loss without the assumption of an intermediate ion/radical complex. However, in similar fragmentations an H/D exchange is observed between the ionic and neutral fragmentation product [31], and for the reaction shown in Scheme 11 the competitiveness of the alkane loss increases with the size of the alkane [32c] as expected for an ion/radical mediated process.

While the rearrangement of the ionic component during the dissociation of the parent ion and the pick-up by the leaving radical of a hydrogen atom neighbouring the bond cleaved do not require necessarily much separation of the components within the intermediate ion/neutral complex, those complexmediated fragmentations are of particular interest in which one partner has to traverse quite large molecular distances to induce an intramolecular ion/neutral reaction. Model calculations [24c,34] show that the locked rotor critical configuration is located at a separation of about $3-4 \AA$ and that the components are held in association until a distance of about $10-15 \AA$. This rather 

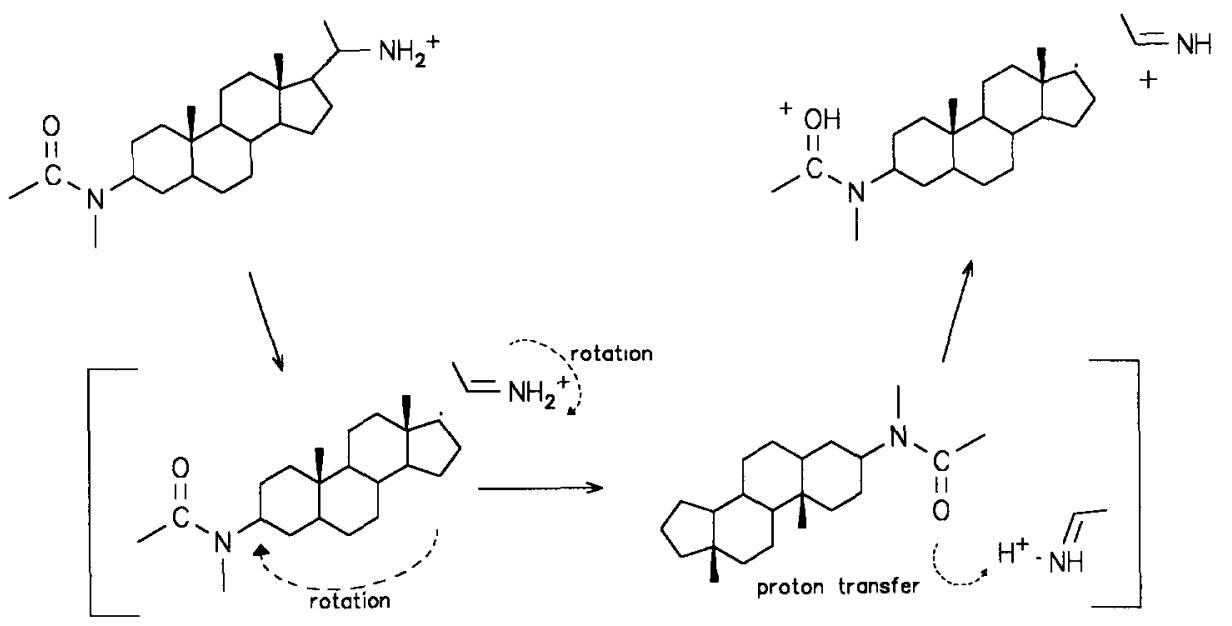

Scheme 12

large distance for an interaction between the ion and the neutral components should enable different spatial reorientations of the components within the complex if the excess energy is small and if the lifetime is long enough. It should be noted that theoretical ab initio calculations of the potential energy of small ion/neutral complexes show an anisotropic force field between the components, as expected by the anisotropy of molecular dipole moments and local polarizabilities. Therefore, special orientations and sometimes "hydrogen-bonded" complexes are particularly stable. It is not yet clear, however, how this anisotropy affects the role of the ion/neutral complexes as reactive intermediates of unimolecular fragmentation. Anyway, "long distance" $H$ transfers [35] have been observed by Longevialle and Botter during the fragmentation of bifunctional steroids carrying a functional group at the rings $\mathrm{A}$ and $\mathrm{D}$ respectively. The Longevialle-Botter model for these fragmentations assumes the initial formation of a small fragment ion by bond cleavage adjacent to one functional group and migration of the ion to the other side of the steroid skeleton within an ion/radical complex. A recent example from Longevialle et al. is shown in Scheme 12 [36]. In this case, the immonium ion initially generated by bond cleavage at ring $\mathrm{D}$ has to span a distance of about $10 \AA$ before it delivers a proton to the amide group at ring A.

Recently we have studied the fragmentations of carbonyl-protonated acetophenones substituted by a methoxymethyl side-chain in the second FFR of a VG-ZAB $2 \mathrm{~F}$ mass spectrometer [37]. These species are conveniently and specifically generated by electron impact induced loss of a methyl radical from the corresponding 2-(methoxymethylphenyl)propanols, and decompose as metastable ions mainly by the four reactions shown in Scheme 13. 


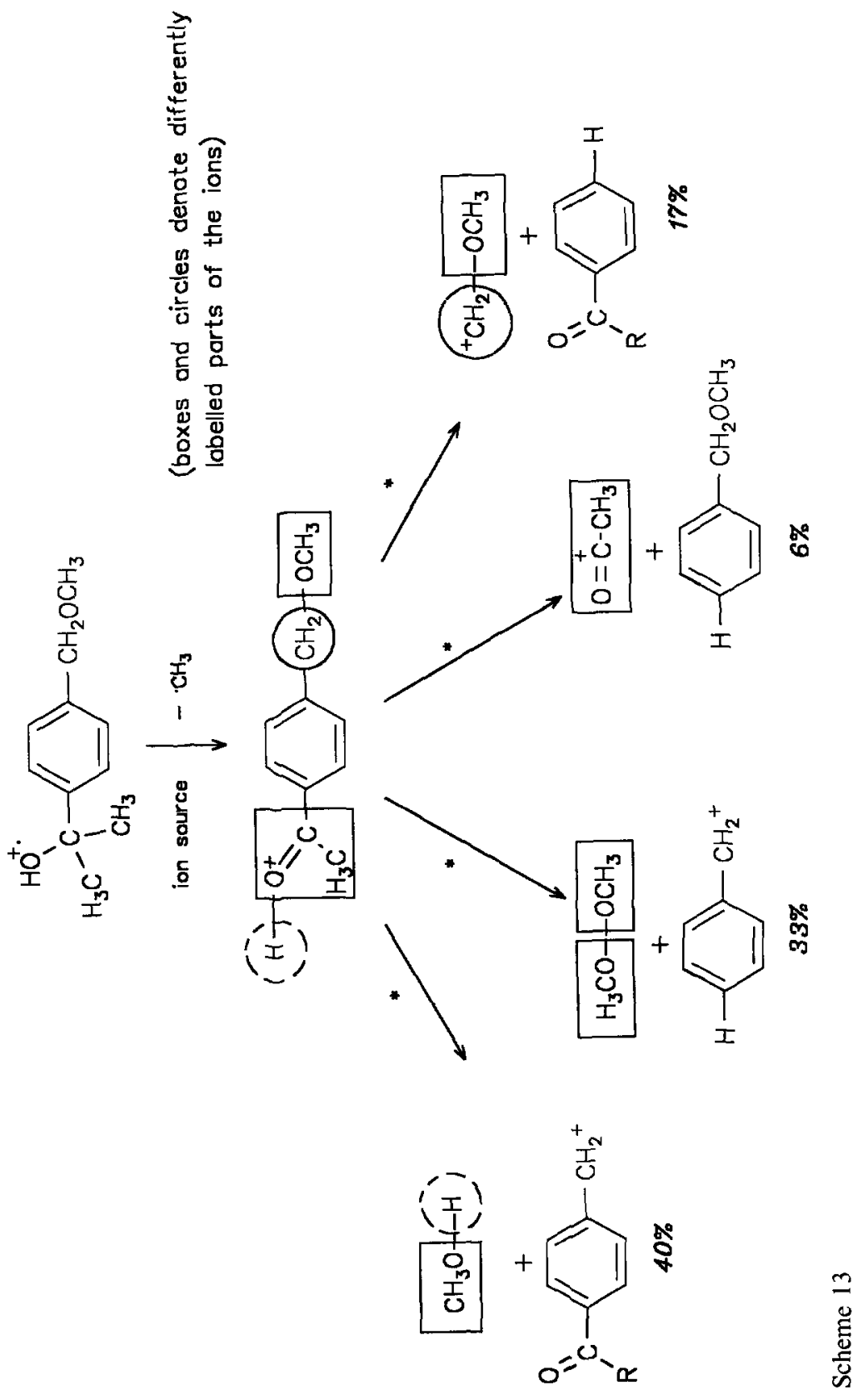


All four fragmentations give stable products, and an estimation of the reaction enthalpies reveals [37] that the fragmentation into a benzyl cation and an ester molecule is especially favourable. An investigation of derivatives labelled by stable isotopes shows that the ions $\mathrm{CH}_{3} \mathrm{OCH}_{2}^{+}$and $\mathrm{CH}_{3} \mathrm{CO}^{+}$are generated from the relevant intact side-chain without any exchange of hydrogen or other atoms. Similarly, the $\mathrm{CH}_{3} \mathrm{COOCH}_{3}$ lost is exclusively composed of the intact methoxy group of the one side-chain and the acetyl group of the other without the extra proton at the carbonyl group, while the methanol contains this proton or one of the four at the benzene ring in a nearly statistical contribution. The latter observation proves unequivocally that the elimination of a methyl acetate molecule is a distinct process and not a combination of subsequent losses of $\mathrm{CH}_{3} \mathrm{OH}$ and $\mathrm{CH}_{2}=\mathrm{C}=\mathrm{O}$ which would result in identical label distributions for methanol loss and ester loss. Furthermore, the exchange between the (mobile) proton originally at the carbonyl group and the hydrogen atoms at the benzene ring prior to the methanol elimination proves the migration of a proton from the carbonyl group to the aromatic ring, giving rise to the reactive intermediates depicted in Scheme 14.

Once the proton is transferred to the benzene ring it exchanges with the other hydrogen atoms at that ring before it migrates to the methoxy group in the side-chain and is eliminated eventually with the methanol molecule. During its ring walk around the benzene ring the proton arrives also at the ipso positions and may cleave either of the two side-chains by protiolytic bond dissociation, a process well known in organic chemistry. This gives rise to the fragment ions $\mathrm{RCO}^{+}\left(\mathrm{R}=\mathrm{CH}_{3}\right)$ and $\mathrm{CH}_{3} \mathrm{OCH}_{2}^{+}$respectively. However, the acetyl cation in particular is held in association with the neutral benzyl methyl ether by the high polarizability of the aromatic system and the dipole moment of the ether group. This ion/neutral complex is the reactive intermediate for the elimination of the ester molecule. A reorientation of the components within the complex, probably assisted by the ether bond dipole, moves the acetyl cation to the ether group. Attaching the acetyl cation to the oxygen atom of the ether group by a Lewis acid-Lewis base reaction and cleavage at the oxonium ion formed gives rise to the observed fragmentation products.

If this mechanism is correct, the elimination of an ester molecule is in direct competition with the formation of an acyl cation by a dissociation of the intermediate complex, and the intensity of the acyl cation in the spectra should increase with the internal energy of the parent ion. This is indeed the case: $70 \mathrm{eV}$ EI mass spectrum of the 2-(4-methoxymethyl-phenyl)propanol as well as the CA spectrum of the protonated acetophenone exhibit only small to moderate peaks at $m / z 91$ (the ionic product of the ester elimination) but large signals for the acetyl cation. Furthermore the mechanism in Scheme 14 implies that the branching between ester elimination and acyl cation formation should depend on the (relative) stability of the acyl cation. This is supported 
by the experimental results [38]. Table 1 shows the MIKE spectra of a series of 4-methoxymethyl-substituted phenones, originally protonated at the carbonyl group. With $\mathrm{R}=\mathrm{CF}_{3}$ neither the elimination of $\mathrm{CF}_{3} \mathrm{COOCH}_{3}$ nor the formation of $\mathrm{CF}_{3} \mathrm{CO}^{+}$is observed because of the thermodynamic instability of this ion. Thus, of the pathways shown in Scheme 14, only the elimination of methanol and of a methoxymethyl cation are observed, indicating that the proton is still migrating from the carbonyl group to the aromatic ring. Exchanging the $\mathrm{CF}_{3}$ group with $\mathrm{H}, \mathrm{CH}_{3}$ and $\mathrm{C}_{2} \mathrm{H}_{5}$ respectively, increases successively the relative abundances for the ester elimination and the formation of $\mathrm{RCO}^{+}$and reduces the methanol elimination. The increasing stability of the $\mathrm{RCO}^{+}$ion enhances the protiolytic cleavage of the acyl side-chain, which is the key step for both processes, in competition to the methanol loss. However, a further increase in the acyl cation stability by substituting $\mathbf{R}$ by $\mathrm{C}_{6} \mathrm{H}_{5}$ increases very much the relative abundance of $\mathrm{RCO}^{+}$only, but decreases the intensity of the ester elimination. This reflects the expected variation of the branching of the intermediate complex between fragmentation by a direct dissociation and an intramolecular ion/molecule reaction.

Table 2 shows the relevant peaks in the MIKE spectra of carbonylprotonated acetylmethoxymethyl arenes with different aromatic systems [39]. These ions have the protonated acetyl side-chain and the methoxymethyl side-chain as far removed as possible, and the distance between the ring $\mathrm{C}$ atom substituted by the protonated acetyl group (starting point of the acetyl ion migration) and the $\mathrm{O}$ atom of the methoxy group (end point) increases from about $5 \AA$ in the benzene derivative to nearly $14 \AA$ in the terphenyl derivative. Nevertheless, the relative abundance of the elimination of methyl acetate, mediated by a complex composed of the acetyl cation and the arylmethyl methyl ether, increases distinctly at the expense of the methanol elimination. Again, the study of deuterated derivatives shows clearly [38] that the ester molecule originates from the acetyl and methoxy group without any H/D exchange, excluding other "conventional" fragmentation mechanisms.

One explanation for the clear increase in the ester elimination process with the size of the aromatic system of the ion is the increasing polarizability of the aromatic moiety with the size. This favours the formation and presumably also the lifetime of the intermediate ion/neutral complex. Such a "size effect" of the neutral component has already been observed in the case of the alkane elimination from aliphatic ether molecular ions [32c] (see Scheme 11), although not as distinct as in the case of the aromatic ions. Therefore, this size effect of the aromatic group is in accord with the proposed mechanism. However, there is another explanation conceivable for the increase in the ester elimination at the expense of the loss of methanol. In the case of the naphthalenic ions all possible positional isomers have been studied [40], and the results show that the branching between the loss of methanol and of methyl acetate, respectively, 


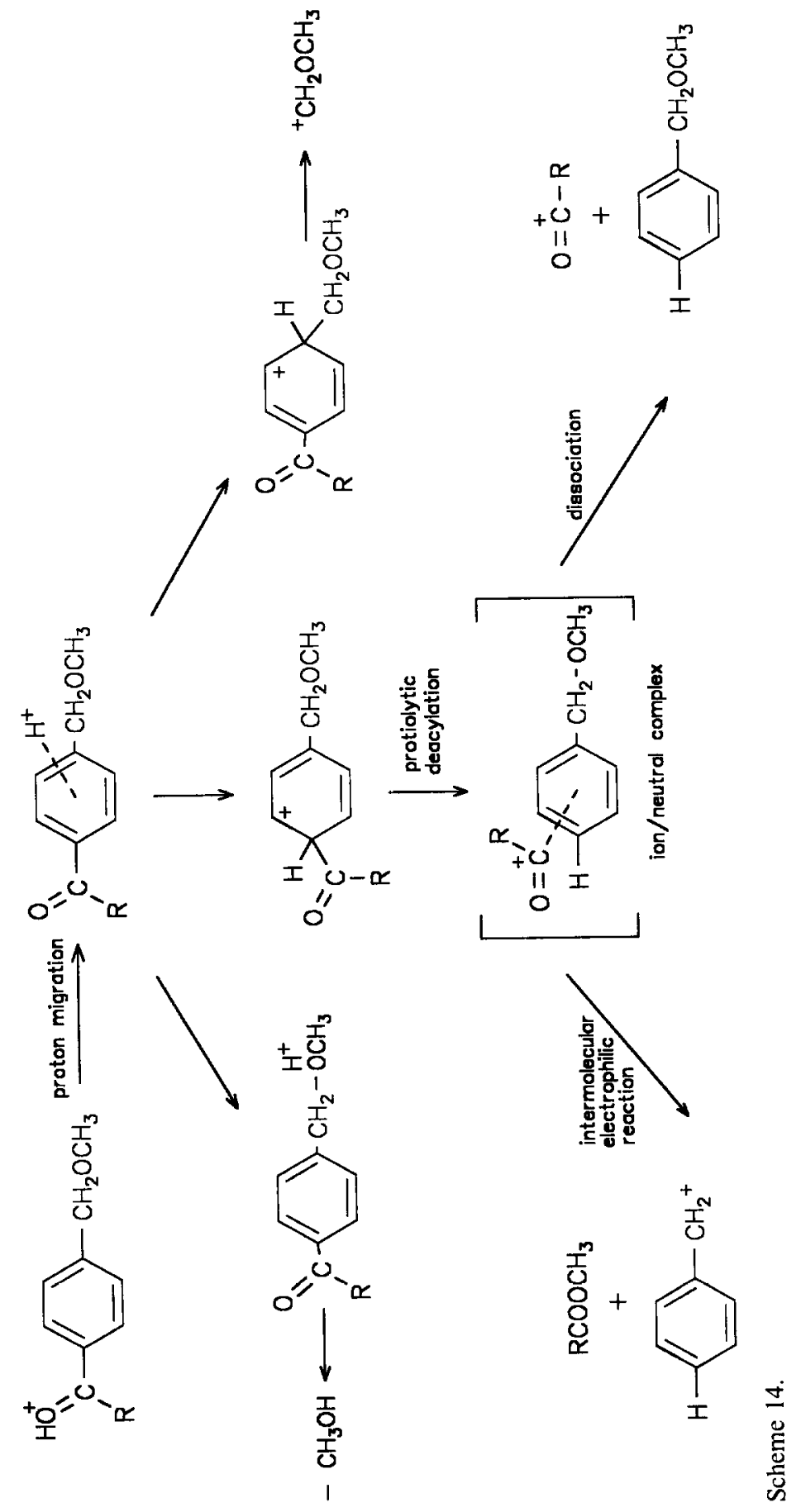


TABLE 1

MIKE spectra of protonated 4-methoxymethylphenones

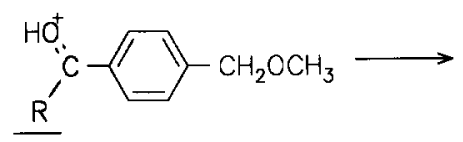

\begin{tabular}{|c|c|c|c|c|c|}
\hline & $-\mathrm{CH}_{3} \mathrm{OH}$ & $-\mathrm{RCOOCH}_{3}$ & $\mathrm{RCO}^{+}$ & $\mathrm{CH}_{3} \mathrm{OCH}_{2}^{+}$ & Other \\
\hline $\mathrm{R}=\mathrm{F}_{3} \mathrm{C}-$ & $49 \%$ & - & - & $16 \%$ & $27 \%\left(-\mathrm{CF}_{3} \mathrm{H}\right)$ \\
\hline $\mathrm{H}-$ & $43 \%$ & $10 \%$ & - & $45 \%$ & $1 \%\left(-\mathrm{CH}_{2} \mathrm{O}\right)$ \\
\hline $\mathrm{H}_{3} \mathrm{C}-$ & $40 \%$ & $33 \%$ & $6 \%$ & $17 \%$ & $3 \%\left(-\mathrm{CH}_{2} \mathrm{O}\right)$ \\
\hline- & $30 \%$ & $31 \%$ & $13 \%$ & $22 \%$ & $4 \%\left(-\mathrm{CH}_{2} \mathrm{O}\right)$ \\
\hline & $20 \%$ & $4 \%$ & $40 \%$ & $13 \%$ & $13 \%$ (- benzene $)$ \\
\hline & $17 \%$ & - & $34 \%$ & $3 \%$ & $32 \%(-$ anısole $)$ \\
\hline & $63 \%$ & $7 \%$ & $27 \%$ & $3 \%$ & - \\
\hline
\end{tabular}

depends strongly on the positions of both side-chains at the naphthalene ring of the parent ion. Two extremes are shown in Table 3, and the high relative abundance of the ester elimination observed for the 1,6-disubstituted ion is not found for the 1,4-disubstituted isomer, which instead prefers to eliminate methanol. An analysis of the correlation between the position of the substituents and the intensity of the different fragmentations reveals that the loss of methanol always prevails if the proton can be transferred directly from the acetyl group to that benzene ring of the naphthalene which is substituted by the methoxymethyl group. The explanation for this effect is a barrier to the "ring-walk" migration of the proton around the naphthalene system imposed by the ring junction. This has been supported by MNDO calculations of the heat of formation of the relevant protomers [38]. Analogously, it is difficult for a proton to cross by successive 1,2-shifts from one benzene ring to the other in the diphenyl and terphenyl systems, as depicted in Scheme 15, because of the energetically unfavourable ipso protomers. In contrast to this, no such energy barriers exist for the migration of the acetyl cation by a reorientation within the ion/neutral complex. Thus the large increase in the relative abundance of the ester elimination in the case of the polycyclic aromatic ions may be also due to a hindrance of the competing elimination of methanol, besides the supportive size effect.

A protiolytic deacylation is the key step for the formation of the acyl 


\section{TABLE 2}

MIKE spectra of carbonyl-protonated acetyl-methoxymethyl arenes

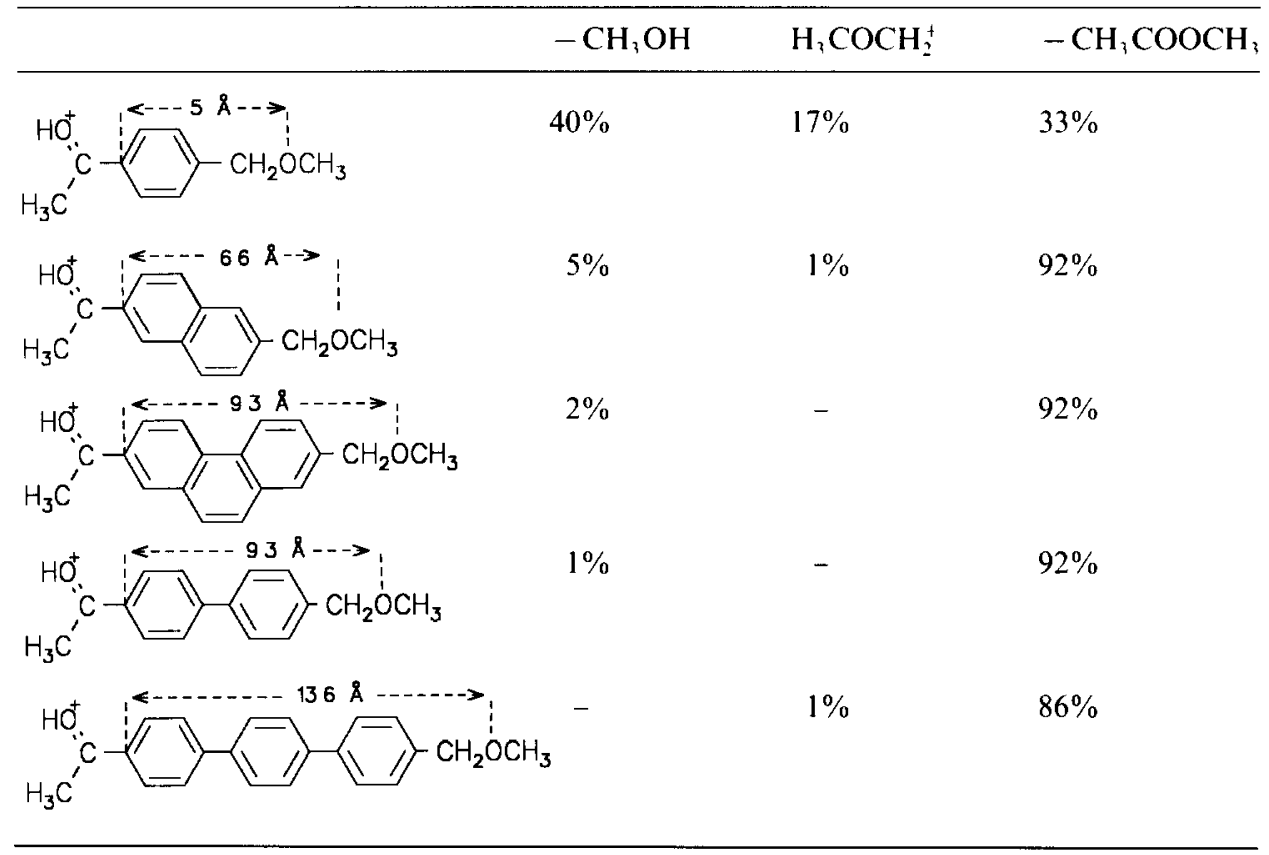

cation/benzyl ether complex in Scheme 14. Protiolytic bond cleavages in arenium ions in solution are common in organic chemistry, in particular for alkylarenes (Scheme 16). Reactive intermediates of these reactions are $\sigma$ complexes and probably also $\pi$ complexes [25]. Similar reactions have been

TABLE 3

Positional effects in the MIKE spectra of carbonyl-protonated acetyl-methoxymethyl arenes

\begin{tabular}{llll} 
& $-\mathrm{CH}_{3} \mathrm{OH}$ & $\mathrm{H}_{3} \mathrm{COCH}_{2}^{+}$ & $-\mathrm{CH}_{3} \mathrm{COOCH}_{3}$ \\
\hline & $40 \%$ & $17 \%$ & $33 \%$ \\
& & & \\
& & & \\
& & & \\
\end{tabular}



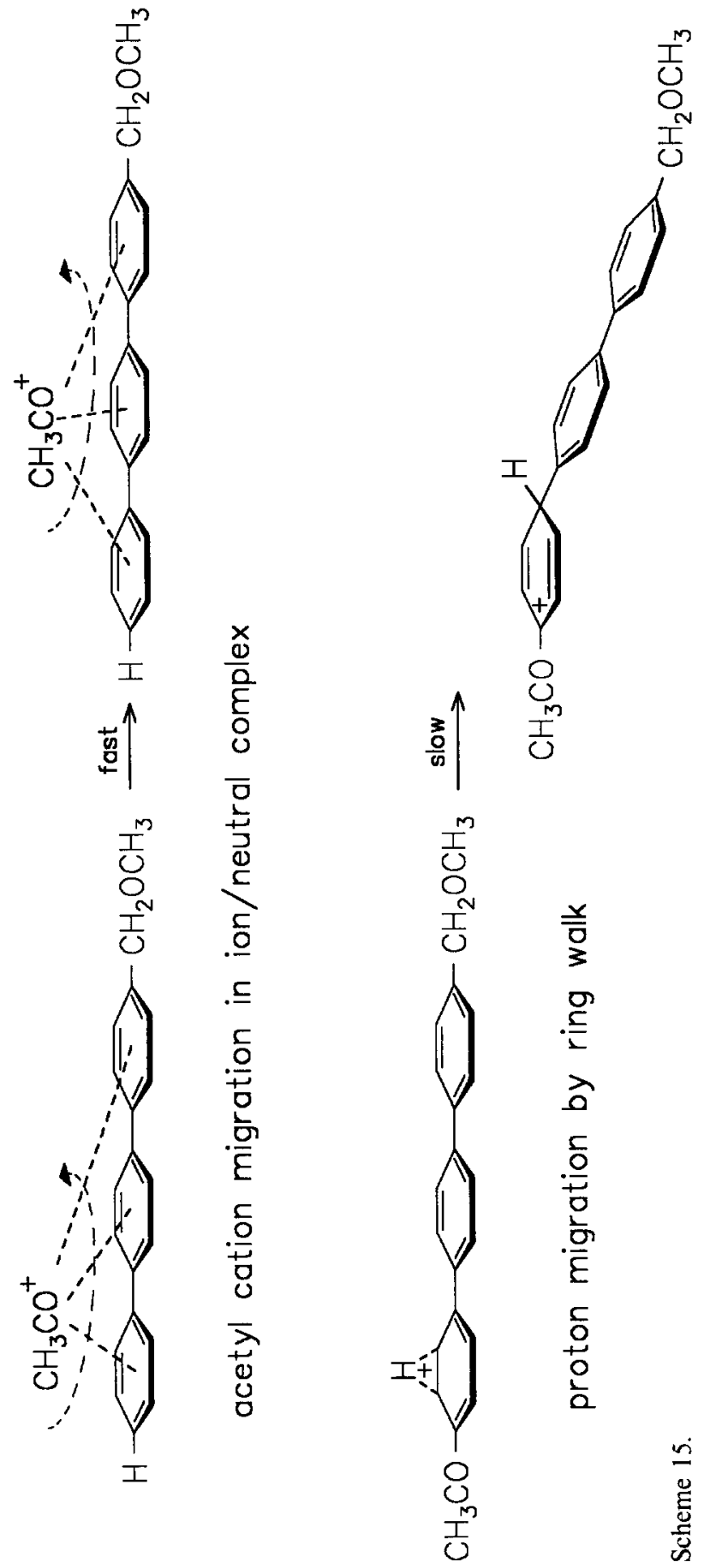


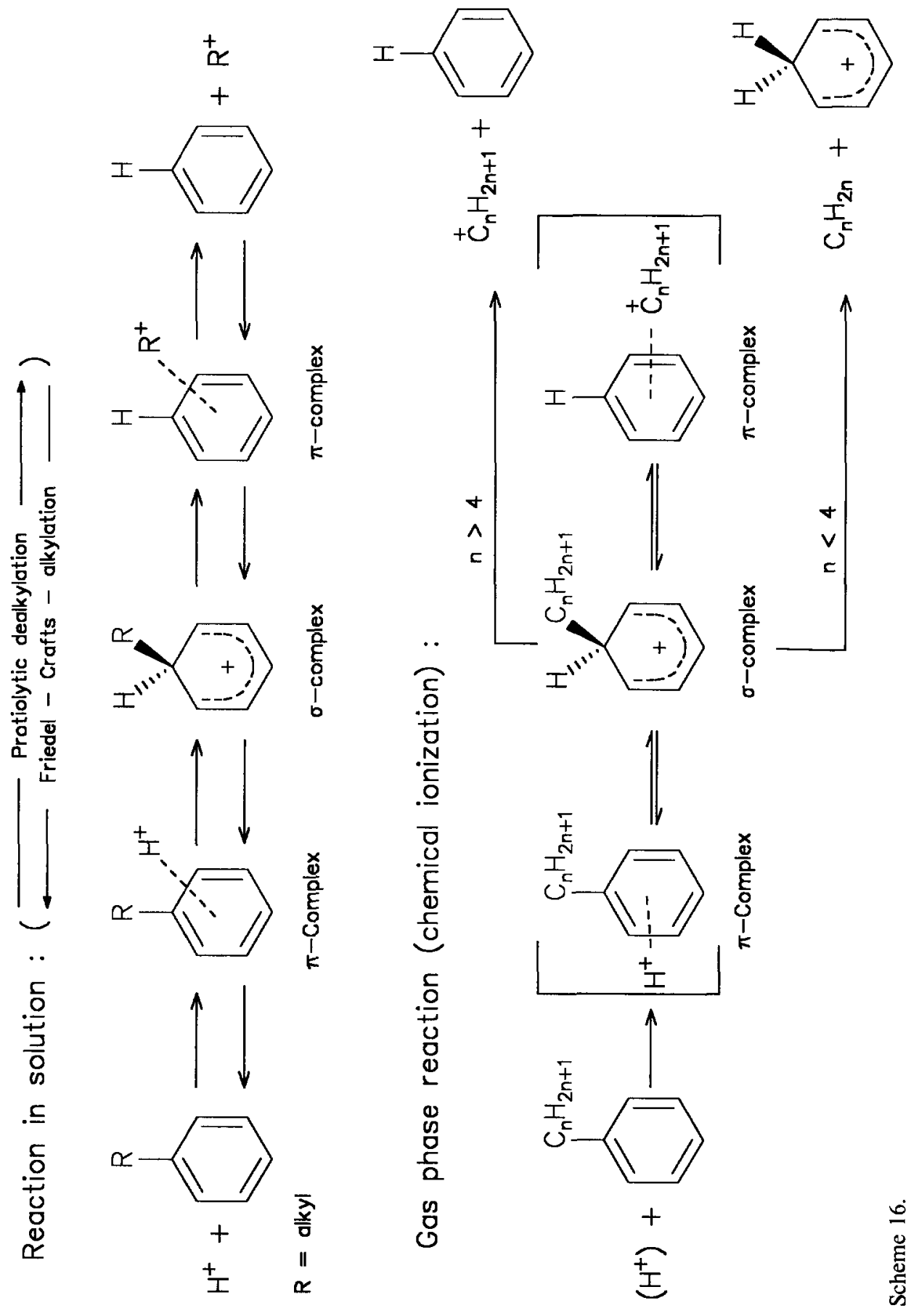


observed in the gas phase [7] during chemical ionization (CI) of alkylbenzenes [41] and by radiolytic studies [42]. Depending on the size of the alkyl sidechain $\mathrm{C}_{n} \mathrm{H}_{2 n+1}$ the $\mathrm{CI}$ mass spectra of alkyl benzenes and the MIKE spectra of protonated alkylbenzenes exhibit intense signals of the benzenium ion $(n \leqslant 4)$ generated by alkene elimination of alkyl cations $(n \geqslant 4)$.

While it is evident that $\sigma$ complexes are reactive intermediates during the decomposition of arenium ions in the gas phase, the role of $\pi$ complexes or intermediate carbenium ion/arene complexes is less clear [7,43]. This problem has been studied by several groups [7,42-44]. It turned out that the carbenium ions generated from the arenium ions have isomerized into the most stable structure possible, and the mechanism can be most conveniently depicted as shown in Scheme 17. Here the $\sigma$ complex formed by the protonation of the alkylbenzene decomposes by protiolytic elimination of the side-chain carbenium ion and the incipient carbenium ion rearranges in an intermediate complex to a more stable isomer. Another possible pathway, depending on the stability of the carbenium ion and the proton affinity of the underlying alkene, is a proton transfer from the carbenium ion to the benzene and elimination of an alkene. This latter reaction could entail an intermediate proton-bound complex between benzene and the alkene.

Although the existence of intermediate carbenium ion/arene complexes or $\pi$ complexes is consistent with these experimental results, the evidence is not as unambiguous as desired. However, additional and convincing proof for intermediate ion/neutral complexes during the protiolytic gas-phase dealkylation has been obtained recently. Audier and co-workers [45] studied the fragmentation of $n$-propylbenzene and isopropylbenzene by $\mathrm{CI}\left(\mathrm{H}_{2} \mathrm{O}\right)$. Under these conditions the MIKE spectrum shows a large signal at $m / z 79$ due to benzenium ions and a small one at $m / z 43$ for $\mathrm{C}_{3} \mathrm{H}_{7}^{+}$, formed by elimination of propene and the isopropyl cation, respectively (Scheme 18). Using deuterated derivatives an $\mathrm{H} / \mathrm{D}$ exchange between the phenyl group and the methyl groups is observed. An example is given in the insert of Scheme 18. For this labelled ion not only the expected mass shift of the ions $\mathrm{m} / \mathrm{z} 79$ to $\mathrm{m} / \mathrm{z} 80$ is observed, but also a distinct amount of ions $m / z 81$ and 82 . Similarly, the ions $m / z 43$ are not only shifted to $m / z 49$ as expected but also to $m / z 48$ and 47 . Clearly an interconversion of a $\mathrm{C}_{3} \mathrm{H}_{7}^{+} / \mathrm{C}_{6} \mathrm{H}_{6}$ and a $\mathrm{C}_{3} \mathrm{H}_{6} / \mathrm{C}_{6} \mathrm{H}_{7}^{+}$complex takes place before either an isopropyl cation or a propene is eliminated, but the precise constitution of the complexes and in particular the mobility of the ionic component remains still somewhat vague.

A proof of the existence of loosely bound ion/neutral complexes in these reactions in addition to $\sigma$ complexes with a fixed orientation of the alkyl group and to proton-bound complexes comes from a study of protonated tert-butylbenzenes carrying additional substituents. Audier et al. [46] investigated inter alia metastable 1-tert-butyl-4-ethylbenzenium ions (Scheme 19) which 

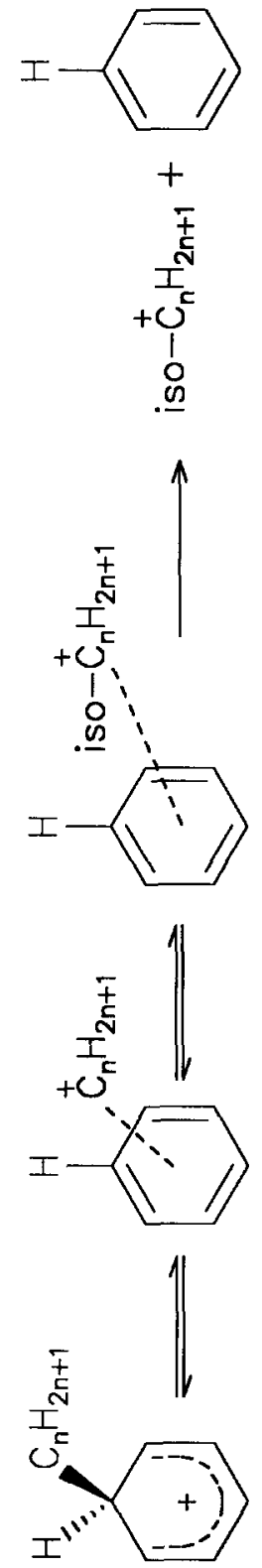

$$
\text { 위 }
$$

$$
\frac{\sqrt{n}}{U^{5}}
$$
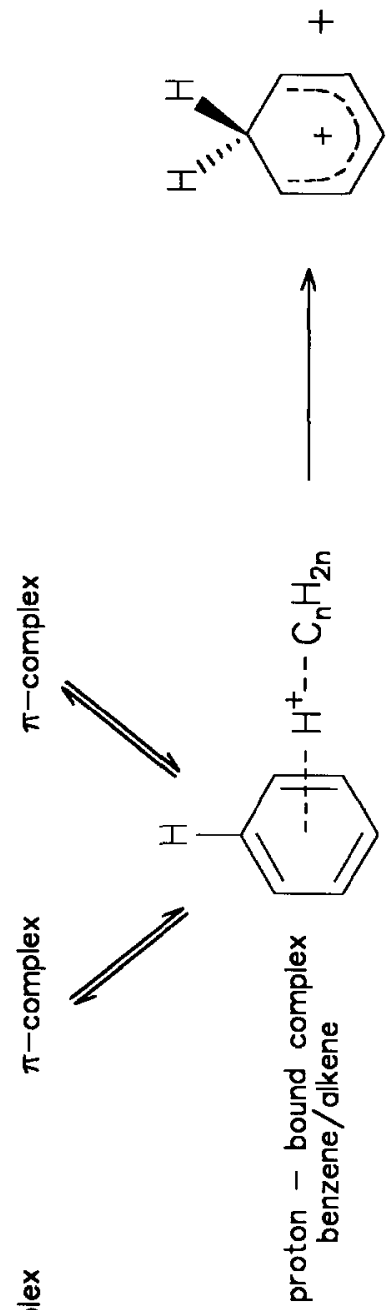

플 

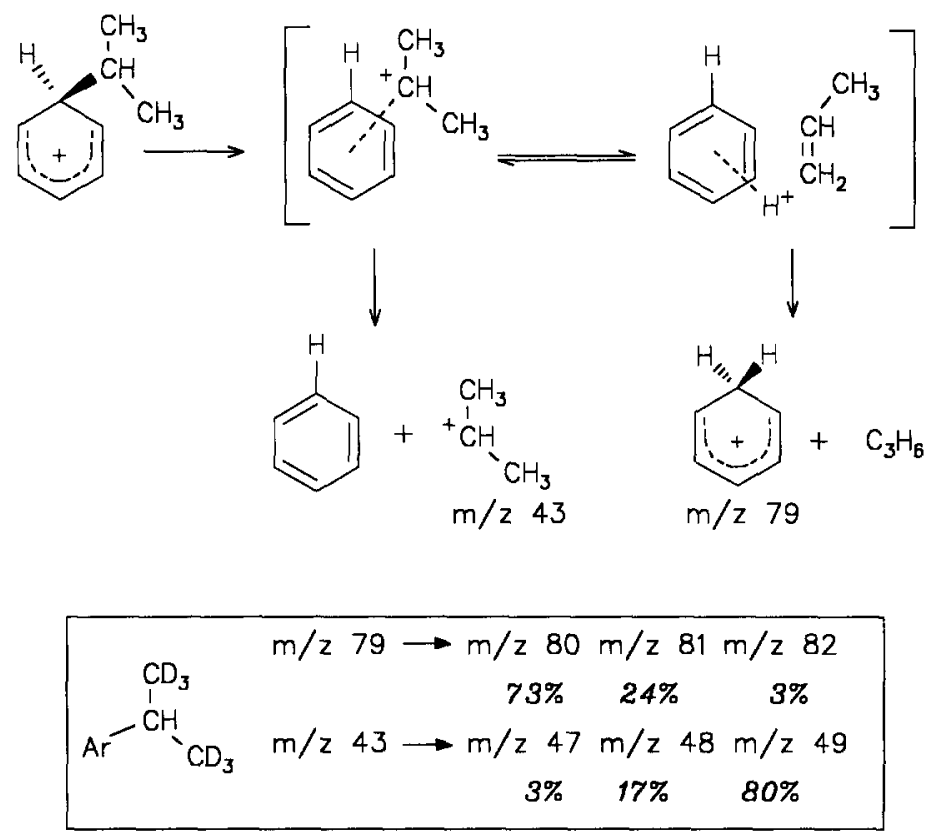

Scheme 18.
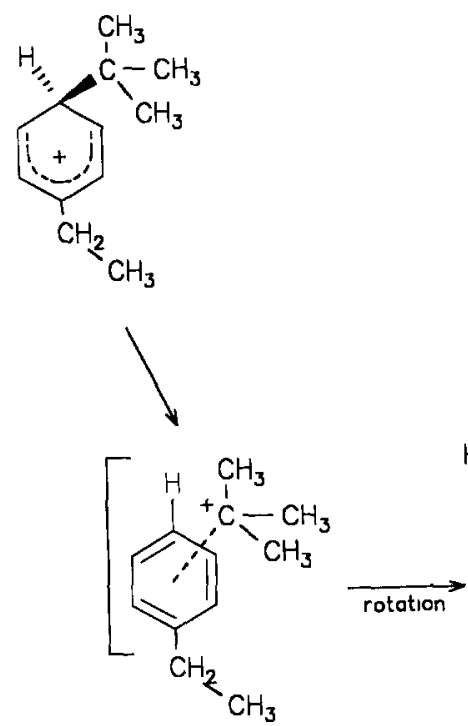

Scheme 19.<smiles>C[C+][C+](C)c1ccccc1</smiles>
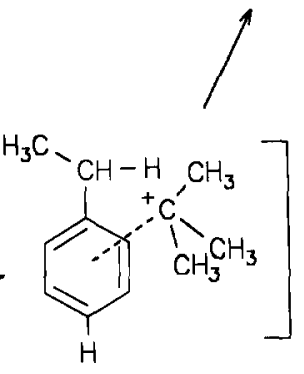


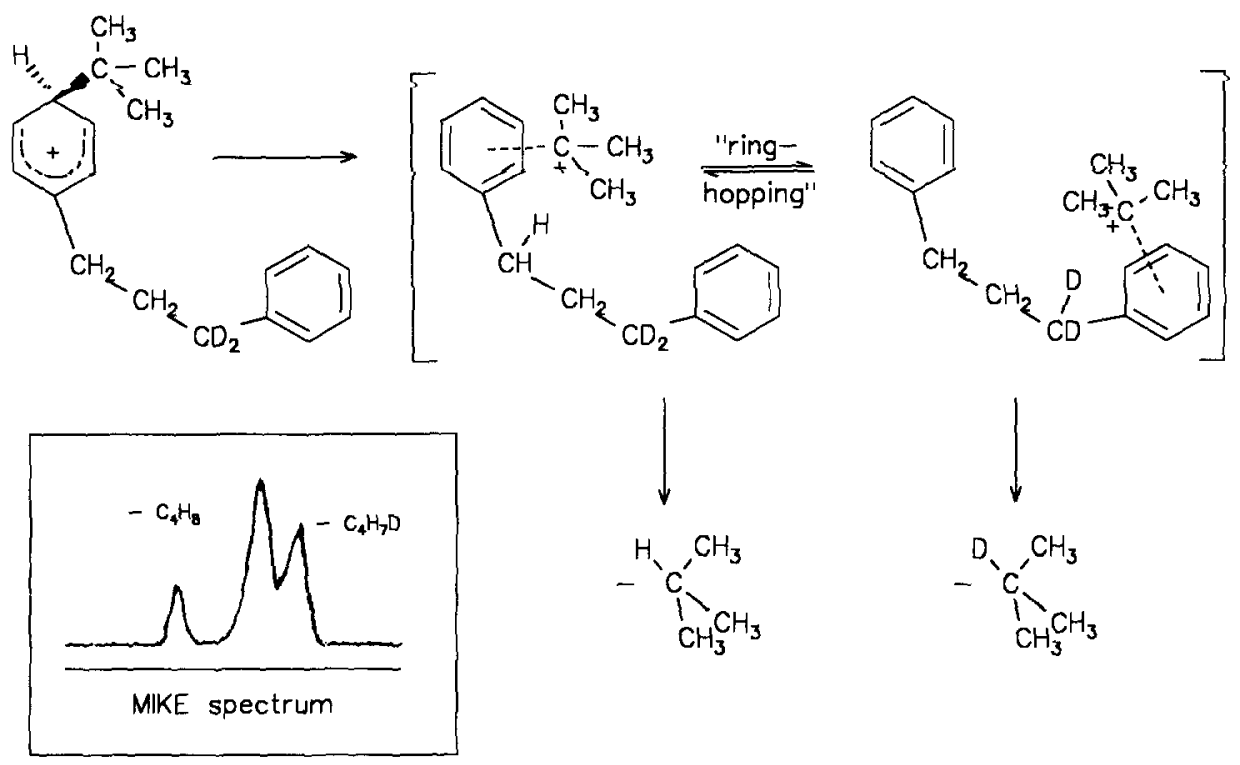

Sctrina 20 .

decompose by loss of $\mathrm{C}_{4} \mathrm{H}_{10}$, very likely isobutane. Labelling with stable isotopes revealed that the isobutane is composed of the tert-butyl side-chain and a hydrogen atom from the $\alpha-\mathrm{CH}_{2}$ of the ethyl group. An estimation of the reaction enthalpies showed that in this case elimination of the alkane is more

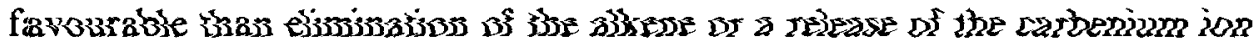
[46]. The mechanism of the alkane elimination is shown in Scheme 10. Obviously a tert-butyl cation/ethylbenzene complex is generated first, and a reorientation of the components brings the tert-butyl cation close to the ethyl side-chain where it picks up a hydride. Thus this reaction is reminiscent of the alkane vs. alkyl radical loss discussed before, but occurs in an even-electron parent ion and by a hydride abstraction instead of a radical reaction.

Recently we could show in a related experiment that tert-butyl cations are indeed able to span quite large molecular distances in carbenium ion/arene complexes [47]. The 1-(4-tert-butylpheny1)-3-phenyipropane (Scheme 20) eliminates also $\mathrm{C}_{4} \mathrm{H}_{10}$ after protonation in a $\mathrm{Cl}$ (isobutane) experiment. This process can be conveniently followed by MIKE spectrometry. The MIKE spectrum of the protonated 1-(4-tert-butylphenyl)-3-phenylpropane contains signals for the loss of $\mathrm{CH}_{3}$ and $\mathrm{C}_{4} \mathrm{H}_{8}$ besides the peak for $\mathrm{C}_{4} \mathrm{H}_{10}$ loss. However, these additional peaks arise from the fragmentation of ${ }^{13} \mathrm{C}$ molecular ions formed concomitant to the nrntsnated snesies Thus slimination $\Omega f \Omega_{4} L_{10}$ is the only reaction of low energy protonated ions.

An investigation of a series of specifically deuterated derivatives of 1-(4-tert- 
butylphenyl)-3-phenylpropane confirms that the elimination of $\mathrm{C}_{4} \mathrm{H}_{10}$ is a specific process between the tert-butyl substituent and one of the $\mathrm{H}$ atoms at the benzylic positions. The derivative shown in Scheme 20 is deuterated at the benzylic position remote from the 4-tert-butylphenyl group. The relevant part of the MIKE spectrum is shown in the small insert of Scheme 20, and it is seen that both $\mathrm{C}_{4} \mathrm{H}_{10}$ and $\mathrm{C}_{4} \mathrm{H}_{9} \mathrm{D}$ are lost, the latter requiring a migration of the tert-butyl cation to the remote benzyl group. The MIKE spectrum of the derivative deuterated at the benzylic position next to the 4-tert-butylphenyl group is nearly identical to that shown in Scheme 20. This means that the intensity difference observed for the loss of $\mathrm{C}_{4} \mathrm{H}_{10}$ and $\mathrm{C}_{4} \mathrm{H}_{9} \mathrm{D}$, respectively, is mostly due to an isotope effect, and that the hydride abstraction by the tert-butyl cation is the rate-determining step of the fragmentation. Furthermore, the 1,3-diphenylpropane unit is "symmetrized" with respect to the elimination of $\mathrm{C}_{4} \mathrm{H}_{10}$, and probably the tert-butyl cation migrates reversibly between the two benzene rings ("ring hopping"). Experiments are currently underway to study the migratory capability of tert-butyl cations and other carbenium ions in related polyaromatic compounds.

\section{FINAL REMARKS}

From the two types of reactive intermediate discussed in this paper the role of the distonic ions is easier to understand. In fact, they are inherent to the early discussion whether the unimolecular fragmentations of molecular ions occur by concerted or stepwise mechanisms. Now that it is known that distonic ions are as stable or even more stable than the conventional molecular ions, in spite of the unusual structures of the former, a stepwise mechanism including distonic ions as reactive intermediates is the more likely choice. The surprising phenomenon, however, is the fast interconversion between certain distonic ions and radical cations of conventional structure, leading to the apparent "symmetrization" of molecular ions discussed in the Introduction. This many be due to the fact that these intramolecular reactions occur in excited ions and that many sterically favoured transition states are accessible in large organic ions. The fast isomerization of distonic ions by hydrogen shifts and by skeletal rearrangements and the dependence of these reactions on the internal energy of the ion is probably one main reason for the distinct variation of mass spectra with the experimental conditions. Thus a knowledge about distonic ions is essential for an understanding of mass spectra.

From the definition used in this account the intermediate ion/neutral complexes are ubiquitous and may look somewhat trivial. In fact, they are seldom substantial for the fragmentation of high energy ions giving rise to the peak pattern of the normal EI mass spectra. Their domain as reactive intermediates are reactions of low energy ions, and probably their importance 
escalates with the size of the parent ions. The fascinating idea about the intermediate ion/neutral complexes is the possibility of preparing easily a broad variety of intimate complexes of low energy to study the effect of a neutral on the reactivity of the attached ion. Recent examples are $\mathrm{S}_{1}^{+} /$arene complexes in which the properties of the arene steers the reactions of the attached $S_{1}^{+}$[48]. Similar effects are expected for other element ions and organic ions, and thus interesting results are to be expected from further research in this area of gas-phase ion chemistry.

\section{ACKNOWLEDGEMENT}

In preparing this account, the help of my friends and colleagues in providing me with published and unpublished material is gratefully acknowledged. I also wish to thank my co-worker and students for their skilful research work in our laboratories over the years and our lively discussions about gas-phase ion chemistry. We thank the Deutsche Forschungsgemeinschaft for the financial assistance of our work.

\section{REFERENCES}

1 M.L. Gross, Adv Mass Spectrom., 11A (1989) 792.

2 (a) F.W. McLafferty (Ed.),Tandem Mass Spectrometry, Wıley, New York, 1983

(b) R.W. McLafferty, Adv. Mass Spectrom., 10A (1985) 493.

3 L. Radom, Org Mass Spectrom., 26 (1991) 359.

4 C.B. Theissling, N.M.M. Nibbering and R.J De Boer, Adv. Mass Spectrom., 5 (1971) 642

5 J.D. McCollum and S. Meyerson, J. Am. Chem. Soc., 81 (1959) 4116.

6 (a) D. Kuck and H.-Fr. Grützmacher, Org. Mass Spectrom., 13 (1978) 81.

(b) D. Kuck and H -Fr. Grützmacher, Org. Mass Spectrom., 13 (1978) 90.

7 D. Kuck, Mass Spectrom. Rev., 9 (1990) 187, 583.

8 S Hammerum, Mass Spectrom. Rev., 7 (1988) 123.

9 D.J McAdoo, Mass Spectrom. Rev., 7 (1988) 363

10 (a) B F. Yates, W.J. Bouma and L. Radom, J. Am. Chem. Soc., 106 (1984) 5805

(b) L. Radom, W J. Bouma and B.F. Yates, Pure Appl. Chem, 58 (1984) 1831.

(c) B F. Yates, J. Bouma and L. Radom, Tetrahedron, 42 (1986) 6225.

11 G Bouchoux, F Djazı, Y. Hoppılliard, P. Jaudon and N. Nouts, Org. Mass Spectrom., 23 (1988) 33

12 (a) N. Mallova and P. Longevialle, J. Am. Soc. Mass Spectrom., 1 (1990) 238.

(b) B. Boukobbal, O Lefevre, P Longevialle and G. Bouchoux, Rapıd Commun. Mass Spectrom., 5 (1991) 330.

13 F W. McLafferty, Interpretation of Mass Spectra, Unıversity Science Books, Mill Valley, CA, 1980.

14 W.J. Richter, J.M. Tesarek and A.L. Burlingame, Adv. Mass Spectrom., 5 (1971) 699.

15 T Björnholm, S Hammerum and D. Kuck, J. Am. Chem. Soc, 110 (1988) 3863.

16 P H. Hemberger, J C. Kleıngeld, K. Levsen, N. Maınzer, A. Mandelbaum, N.M.M. Nibberıng, H. Schwarz, R. Weber, A. Weisz and C Wesdemiotıs, J. Am. Chem Soc., 102 (1980) 3736. 
17 D.J. McAdoo, C.E. Hudson, T. Lin, L.L. Griffin and J.C. Traeger, Int. J. Mass Spectrom. Ion Processes, 87 (1989) 61.

18 (a) R Wolf, A.-M. Dommröse and H.-Fr. Grützmacher, Org. Mass. Spectrom., 23 (1988) 26.

(b) R. Wolf and H.-Fr. Grützmacher, Org. Mass Spectrom., 24 (1989) 398.

19 P.C. Burger, K. van den Berg, H. Visser and J.K. Terlouw, Int. J. Mass Spectrom. Ion Processes, 101 (1990) 83.

20 M.A. Winnik, Org. Mass Spectrom., 9 (1974) 920.

21 G. Bouchoux, J. Tortajada, J. Dagout and J. Fillaux, Org. Mass Spectrom., 22 (1987) 451.

22 C.E. Hudson, T. Lin and D J McAdoo, Org. Mass Spectrom., 22 (1987) 311.

23 M Masur, A. Sprafke and H.-Fr. Grützmacher, Org. Mass Spectrom., 22 (1987) 307

24 (a) T.H. Morton, Tetrahedron, 38 (1982) 3195

(b) E.W. Redman and T.H. Morton, J. Am. Chem. Soc., 108 (1986) 5701.

(c) E.L. Chronister and T.H. Morton, J. Am. Chem. Soc., 112 (1990) 133.

(d) R.W. Kondrat and T.H. Morton, Org. Mass Spectrom., 26 (1991) 410.

25 (a) P. Vogel, Carbocation Chemistry, Elsevier, Amsterdam, 1985.

(b) T.H. Lowry and K. Schueller Richardson, Mechanism and Theory in Organic Chemistry, 3rd edn., Harper and Row, New York, 1987.

26 J D. Shao, T. Baer and D.K. Lewis, J. Phys. Chem., 92 (1988) 5123.

27 J H. Stewart, R.H. Shapiro, C.H. DePuy and V. Bierbaum, J. Am. Chem. Soc., 99 (1977) 7650 .

28 (a) J.F. Garvey and R.B. Bernstein, J. Am. Chem. Soc., 109 (1987) 1921.

(b) B. Brutschy, J. Phys. Chem., 94 (1990) 8637

(c) A.W. Castleman, Jr., W.B. Tzeng, S. Wei and S. Morgan, J. Chem. Soc., Faraday Trans., 86 (1990) 2417

29 R.D. Bowen and D.H. Williams, J. Am. Chem. Soc., 99 (1977) 6822.

30 D.H Williams, Acc. Chem. Res., 10 (1977) 280.

31 (a) S. Hammerum, J. Chem. Soc., Chem. Commun., (1988) 858

(b) S. Hammerum and H.E. Audier, J. Chem. Soc., Chem. Commun., (1988) 860.

32 (a) D J. McAdoo and M.P. Barbalas, Int. J. Mass Spectrom. Ion Phys., 36 (1980) 281.

(b) J.C. Traeger, C.E. Hudson and D.J. McAdoo, J. Phys. Chem., 94 (1990) 5714.

(c) D.J. McAdoo, J.C. Traeger, C.E. Hudson, A. Grose and L.L. Griffin, J. Am. Soc. Mass Spectrom., 2 (1991) 261.

33 (a) M C Bisonnette, M. George and J.L. Holmes, Int. J. Mass. Spectrom. Ion Processes, 101 (1990) 309.

(b) M.C. Bisonnette, M. George and J.L. Holmes, Int J. Mass Spectrom., 25 (1990) 689.

34 T.H. Morton, Org. Mass Spectrom., 26 (1991) 18.

35 P. Longevialle and R. Botter, Org. Mass Spectrom., 18 (1983) 1 (and references cited therein).

36 P. Longevialle, G. Bouchoux and Y. Hoppllıard, Org. Mass Spectrom., 25 (1990) 527.

37 U. Filges and H.-Fr. Grützmacher, Org. Mass Spectrom., 22 (1987) 444.

38 H.-Fr. Grützmacher, G. Thielking, D. Wittneben and D Eikenberg, Int. J. Mass Spectrom. Ion Processes, 90 (1990) 378.

39 U. Filges, G. Thielkıng and H.-Fr. Grützmacher, J. Am. Soc. Mass Spectrom , 3 (1992) in press.

40 U. Filges and H.-Fr. Grützmacher, Int. J. Mass Spectrom. Ion Processes, 83 (1988) 111.

41 (a) J.A. Herman and A.G. Harrıson, Org. Mass Spectrom., 16 (1981) 423.

(b) A.G. Harrison, Can. J. Chem., 64 (1986) 1051.

42 (a) F. Cacace, in P. Ausloos (Ed.), Kinetics of Ion-Molecule Reactions, Plenum, New York, 1979. 
(b) F. Cacace, Acc. Chem. Res., 21 (1988) 215.

43 R.W. Holman and M.L. Gross, J. Am. Chem. Soc., 111 (1989) 3560 (and references cited therein).

44 (a) G. Prior, Diplomarbeit Unıversität Bıelefeld, 1987.

(b) H. Buker, Diplomarbeit Unıversität Bielefeld, 1987.

(c) D Kuck, G. Prior, H.-Fr. Grutzmacher, D.R. Müler and W.J. Richter, Adv. Mass Spectrom, 11 A (1989) 750.

45 D. Berthomieu, H.E Audier, J.-P. Denhez, C. Monteiro and P Mourges, Org Mass Spectrom., 26 (1991) 271.

46 H E. Audier, C. Monteiro, P. Mourgues and D. Berthomıu, Org Mass Spectrom., 25 (1990) 245.

47 D. Kuck, C. Matthıas and H.-Fr. Grützmacher, unpublished work

48 D K. Bohme, unpublished result, 1991. 